\title{
BMI and all cause mortality: systematic review and non-linear dose-response meta-analysis of 230 cohort studies with 3.74 million deaths among 30.3 million participants
}

\author{
Dagfinn Aune, ${ }^{1,2}$ Abhijit Sen, ${ }^{1}$ Manya Prasad, ${ }^{3}$ Teresa Norat, ${ }^{2}$ Imre Janszky, ${ }^{1}$ Serena Tonstad, ${ }^{3}$ \\ Pål Romundstad, ${ }^{1}$ Lars J Vatten ${ }^{1}$
}

Department of Public Health and General Practice, Faculty of Medicine, Norwegian University of Science and Technology,

Trondheim, Norway

2Department of Epidemiology and Biostatistics, Imperial College, London, UK

3Department of Community Medicine, Postgraduate

Institute of Medical Sciences,

Rohtak, Haryana, India

4Section of Preventive

Cardiology, Department of

Endocrinology, Morbid Obesity and Preventive Medicine, Oslo University Hospital Ullevål,

Oslo, Norway

Correspondence to: D Aune, Department of Epidemiology and Biostatistics, School of

Public Health, Imperial College London, London W2 1PG, UK d. aune@imperial.ac.uk

Additional material is published online only. To view please visit the journal online.

Cite this as: $B M$ J 2016;353:i2156 http://dx.doi.org/10.1136/bmj.i2156

Accepted: 24 March 2016

\section{ABSTRACT}

\section{OBJECTIVE}

To conduct a systematic review and meta-analysis of cohort studies of body mass index (BMI) and the risk of all cause mortality, and to clarify the shape and the nadir of the dose-response curve, and the influence on the results of confounding from smoking, weight loss associated with disease, and preclinical disease.

DATA SOURCES

PubMed and Embase databases searched up to 23 September 2015.

\section{STUDY SELECTION}

Cohort studies that reported adjusted risk estimates for at least three categories of BMI in relation to all cause mortality.

\section{DATA SYNTHESIS}

Summary relative risks were calculated with random effects models. Non-linear associations were explored with fractional polynomial models.

\section{RESULTS}

230 cohort studies (207 publications) were included. The analysis of never smokers included 53 cohort studies (44 risk estimates) with $>738144$ deaths and >9976077 participants. The analysis of all participants included 228 cohort studies (198 risk estimates) with >3744722 deaths among 30233329 participants. The summary relative risk for a 5 unit increment in BMI was 1.18 (95\% confidence interval 1.15 to $1.21 ; I^{2}=95 \%$, $\mathrm{n}=44)$ among never smokers, 1.21 (1.18 to $1.25 ; \mathrm{I}^{2}=93 \%$, $\mathrm{n}=25$ ) among healthy never smokers, 1.27 (1.21 to 1.33; $\left.\mathrm{I}^{2}=89 \%, \mathrm{n}=11\right)$ among healthy never smokers with

\section{WHAT IS ALREADY KNOWN ON THIS TOPIC}

A high $B M I$ is associated with increased risk of all cause mortality

A recent meta-analysis found a reduced risk with overweight and that only obesity grade 2 ( $\mathrm{BMI} \geq 35$ ) increased risk, but the results could have been confounded by smoking and prevalent and prediagnostic disease and biased because of exclusion of many large cohort studies

\section{WHAT THIS STUDY ADDS}

In never smokers and healthy never smokers, there was a s shaped association between BMI and mortality, and the lowest risk was observed at BMI 23-24 and

22-23, respectively

When analysis was restricted to studies with a longer duration of follow-up (to reduce confounding by prediagnostic weight loss) the lowest risk was observed with BMI 20-22

Lack of exclusion of ever smokers, people with prevalent and prediagnostic disease, or early follow-up could bias the associations between BMI and mortality towards a more $U$ shaped association

exclusion of early follow-up, and 1.05 (1.04 to 1.07; $\mathrm{I}^{2}=97 \%, \mathrm{n}=198$ ) among all participants. There was a J shaped dose-response relation in never smokers $\left(\mathrm{P}_{\text {non-linearity }}<0.001\right)$, and the lowest risk was observed at BMI 23-24 in never smokers, 22-23 in healthy never smokers, and 20-22 in studies of never smokers with $\geq 20$ years' follow-up. In contrast there was a $U$ shaped association between BMI and mortality in analyses with a greater potential for bias including all participants, current, former, or ever smokers, and in studies with a short duration of follow-up ( $<5$ years or $<10$ years), or with moderate study quality scores.

\section{CONCLUSION}

Overweight and obesity is associated with increased risk of all cause mortality and the nadir of the curve was observed at BMI 23-24 among never smokers, 22-23 among healthy never smokers, and 20-22 with longer durations of follow-up. The increased risk of mortality observed in underweight people could at least partly be caused by residual confounding from prediagnostic disease. Lack of exclusion of ever smokers, people with prevalent and preclinical disease, and early follow-up could bias the results towards a more $U$ shaped association.

\section{Introduction}

The prevalence of overweight and obesity has increased rapidly over the past decades throughout the world. ${ }^{1}$ This has raised serious public health concerns because of the association between overweight and obesity and increased risk of a wide range of chronic diseases, including cardiovascular diseases, ${ }^{2}$ type 2 diabetes, ${ }^{3}$ several types of cancer, ${ }^{4-8}$ gallbladder disease, ${ }^{9}$ gout, ${ }^{10}$ osteoarthritis, ${ }^{11}$ and several other conditions, ${ }^{11-13}$ as well as all cause mortality. ${ }^{214}$

Though many studies have shown an increased risk of all cause mortality with greater adiposity as measured by body mass index (BMI), ${ }^{15-24}$ questions remain about the shape of the dose-response relation. Several large scale prospective studies ${ }^{15-24}$ and pooled analyses (each with 900000 to 1.46 million participants) ${ }^{21425}$ have reported increased risk of all cause mortality with greater BMI, and most of these found the lowest risk among participants with BMI in the range of 20 or 22.5 to 24.9. A large meta-analysis of 97 cohort studies with 2.88 million participants and 270000 deaths, which used the WHO cut-off points for overweight and obesity, however, found summary hazard ratios of 0.94 (95\% confidence interval 0.90 to 0.97 ), 0.97 (0.90 to 1.04), and 1.34 (1.21 to 1.47) for a BMI of $25-<30,30-<35$, and $\geq 35$, respectively, suggesting a protective effect of overweight 
on mortality and that only severely obese people are at increased risk of mortality. ${ }^{26}$ That review, however, had several limitations-for example, it excluded several large and some smaller studies including $>5.4$ million participants and $>1.1$ million deaths that used more refined categorisations of BMI than the WHO categorisations. ${ }^{15} 16$ 18-20 24 27-54 Thus more deaths and participants were excluded than included in the analysis, and questions have been raised with regard to the validity of the findings. ${ }^{55}$ In addition, a large number of additional cohorts were either missed by the search or excluded from the analysis, ${ }^{56-65}$ and at least 53 additional studies have since been published, including $>2.3$ million deaths and >21.6 million participants. ${ }^{232465-115}$ An updated analysis is therefore warranted.

It is well known that smoking strongly increases risk of mortality and many specific causes of death, ${ }^{116117}$ and there is therefore a great potential for residual confounding by smoking as it is typically also associated with lower weight. ${ }^{118}$ Indeed, many studies have reported a different shape of the dose-response relation between BMI and mortality when the analysis is restricted to people who have never smoked or in comparisons between smokers and never smokers, ${ }^{214-22} 2477$ but this was not adequately dealt with in the previous meta-analysis. ${ }^{26}$ Furthermore, confounding by prevalent or undiagnosed illness could also have biased the results. It is well known that many chronic diseases (which increase the risk of death) lead to weight loss. ${ }^{119}$ Weight loss can precede a diagnosis of disease by many years and because of such preclinical weight loss the associations between low BMI and increased mortality might at least partly be caused by confounding by preclinical disease. ${ }^{120}$ Such bias might be avoided by the exclusion of people with prevalent disease at baseline, by exclusion of the early follow-up period of the studies, and by stratifying studies by duration of follow-up, but the most recent meta-analysis did not conduct such subgroup or sensitivity analyses. ${ }^{26}$

For these reasons we conducted a systematic review and dose-response meta-analysis of published cohort studies to clarify the strength and the shape of the dose-response relation between BMI and all cause mortality, the potential confounding effects of smoking, and whether prevalent disease, exclusion of early follow-up, or stratification by duration of follow-up, or the quality of the studies influenced the association between BMI and all cause mortality. We used fractional polynomial models to assess the association between BMI and mortality, and this allowed for inclusion of all relevant studies reporting results for three or more categories of BMI and not only those reporting results using the $\mathrm{WHO}$ criteria for categorisation of BMI.

\section{Methods}

\section{Search strategy and inclusion criteria}

We searched PubMed and Embase up to 23 September 2015 for eligible studies (DA, AS), using wide search terms (appendix 1). We followed standard criteria for conducting and reporting meta-analyses. ${ }^{121}$ In addition, we searched the reference lists of a previous meta- analysis $^{26}$ for further studies. Study quality was assessed with the Newcastle-Ottawa scale. ${ }^{122}$

\section{Patient involvement}

No patients were involved in setting the research question or the outcome measures, nor were they involved in developing plans for design, or implementation of the study. No patients were asked to advise on interpretation or writing up of results. There are no plans to disseminate the results of the research to study participants or the relevant patient community.

\section{Study selection}

We included cohort studies of the association between BMI and risk of all cause mortality published in English language and excluded abstract only publications and grey literature. In each publication, adjusted relative risk estimates (hazard ratios or risk ratios) for three or more BMI categories had to be available, either with the 95\% confidence intervals or with the information to calculate them. The dose-response analysis, a quantitative measure of the exposure (BMI), also had to be available. Studies from populations living in the community were included, while studies that included only patients (for example, those with diabetes, stroke, heart disease, and cancer), nursing home residents, and disabled people were excluded. When multiple publications were published from the same study, in general we used the publication with the largest number of deaths. Exceptions to this rule were made when publications with smaller number of deaths provided more detailed analyses with restriction to never smokers, healthy people, and/or exclusion of early follow-up than the publications with larger number of deaths. In the analysis of never smokers, the definition of never smokers was strict so we did not include data from studies that combined never smokers and former smokers who had quit for a long duration. When more detailed analyses (restricted to never smokers or other subgroups) were published in an overlapping publication but not in the publication used for the main analysis we used the information from the overlapping publication in the specific analysis, but each study was included only once in each analysis. Studies that reported only a continuous linear risk estimate were excluded as there is evidence that the association between BMI and mortality is non-linear. A list of the excluded studies and reasons for exclusion is provided in table A in appendix 2.

\section{Data extraction}

We extracted the following data from each study: the first author's last name, publication year, country or region where the study was conducted, study period, sample size, number of deaths/participants, whether exclusions were made for prevalent disease, whether exclusions were made for early follow-up, BMI and any subgroup, exposure level, relative risks and 95\% confidence intervals for categories of BMI, and variables adjusted for in the analysis. One author (DA) extracted data, and another author (MP) checked them for accuracy. For one study ${ }^{16}$ we contacted the authors for clarification of which studies were included in the analysis. 


\section{Statistical methods}

We used a random effects model to calculate summary relative risks and 95\% confidence intervals for a 5 unit increment in BMI. ${ }^{123}$ For the primary analysis we used the model from each study that had the greatest degree of control for potential confounding, with the exception of studies that also adjusted mutually between BMI and waist circumference and waist to hip ratio or that adjusted for potentially intermediate variables such as diabetes, hypertension, and serum cholesterol, for which we used the multivariate model without such adjustment if available. If the alternative model was adjusted only for age and the multivariate model included other confounders as well, we chose the multivariate model with intermediates. We estimated the average of the natural logarithm of the relative risks and weighted the relative risk from each study according to the method of DerSimonian and Laird. ${ }^{123}$ A two tailed $\mathrm{P}<0.05$ was considered significant. If studies reported results separately for men and women or other subgroups we combined the subgroup specific estimates using a fixed effects model to generate an estimate for both subgroups combined so that each study was represented only once in the analyses.

We used the method described by Greenland and Longnecker ${ }^{124}$ for the linear dose-response analysis of BMI and mortality and calculated study specific slopes (linear trends) and 95\% confidence intervals from the natural logs of the reported relative risks and confidence intervals across categories of BMI. When the reference category was not the lowest category (because, for example, of power issues) we excluded the categories below the reference category for the linear dose-response analysis to model the association between higher BMI and mortality. The mean or median BMI level in each category was assigned to the corresponding relative risk for each study, and for studies that reported the exposures in ranges we used the midpoint of the upper and the lower cut-off point. When upper and lower categories were open ended or had extreme upper or lower values, we used the width of the adjacent category to calculate an upper or lower bound. When studies reported analyses by the WHO categories of overweight and obesity we used a BMI of 15 as a lower bound for the underweight category $(<18.5)$ and 18.5 as the lower bound for the normal weight category $(<25)$. A potential non-linear dose-response relation between BMI in relation to mortality was examined by using fractional polynomial models. ${ }^{125}$ We determined the best fitting second order fractional polynomial regression model, defined as the one with the lowest deviance. A likelihood ratio test assessed the difference between the non-linear and linear models to test for non-linearity. ${ }^{125}$ For the non-linear dose-response analysis we included all categories of BMI (even the underweight categories) to model the association between BMI and mortality across the full BMI range and used the method of Hamling and colleagues to convert risk estimates when the lowest category was not the reference category. ${ }^{126}$ The analyses were re-scaled so the reference category was a BMI of 23, which seemed to be the nadir of the curve among never smokers, so there was no loss of statistical power from these re-calculations. The fractional polynomial method estimated a dose-response curve for each study across the BMI values observed in the whole dataset (which was extrapolated across the full BMI range for studies with a limited BMI range), so all studies contributed to the pooled risk estimates across the full BMI range. The dose-response curves for each of the individual studies were then pooled into an overall dose-response curve, which are the curves showed in the non-linear figures. The relative risk estimates in the tables were based on the non-linear figures but show risk estimates for selected BMI values.

We conducted subgroup and meta-regression analyses to investigate potential sources of heterogeneity and heterogeneity between studies quantitatively assessed by the $Q$ test and $I^{2}{ }^{127}$ Small study effects, such as publication bias, were assessed by inspection of the funnel plots for asymmetry and with Egger's test ${ }^{128}$ and Begg's test, ${ }^{129}$ with the results considered to indicate small study effects when $\mathrm{P}<0.10$. To avoid potential confounding by smoking we present results on BMI and mortality in never smokers as the primary analysis, and conducted further restrictions to healthy never smokers and healthy never smokers with exclusion of the early follow-up in supplementary analyses (here and throughout, healthy never smokers refers to never smokers who were healthy at baseline). We also report results among all participants (not excluding smokers) for comparison with the most recent meta-analysis ${ }^{26}$ and in smokers in secondary analyses. Further subgroup analyses were conducted by sex, method of assessment of weight and height, duration of follow-up, geographical location, number of deaths, study quality and adjustment for confounders, adjustment for mediators, and restriction to studies with appropriate adjustment for age, smoking, alcohol, and physical activity, but without adjustment for prevalent disease or intermediate factors. Because we did not have access to the original data and because not every study excluded early follow-up we also conducted analyses stratified by duration of follow-up to investigate the influence of undiagnosed disease on the results. As the number of deaths increases with increasing duration of follow-up, the early follow-up (when participants with undiagnosed disease most likely would have died) will account for a smaller and smaller proportion of the total deaths the longer the duration of follow-up is. As preclinical weight loss can precede the diagnosis of disease by many years, stratification by duration of follow-up can allow for assessments of the longer term impact of confounding by undiagnosed disease. We used Stata, version 12.0 (Stata Corp, College Station, TX) for the statistical analyses.

\section{Results}

From a total of 112173 records identified by the search we included 207 publications ${ }^{16-2427-5456-115130-239}$ with 230 cohort studies including >3748549 deaths among 30361918 participants in the meta-analysis of BMI and risk of all cause mortality (table B in appendix 2; fig 1). Table 1 summarises the main characteristics (number of 


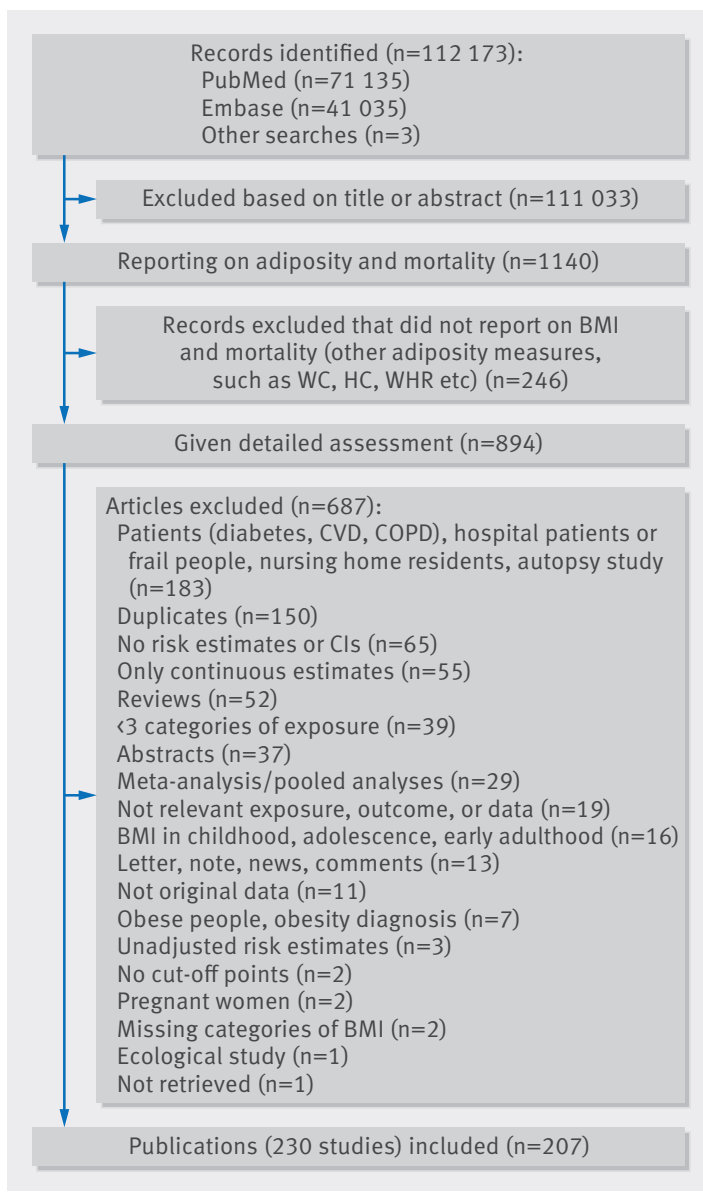

Fig 1 | Flow chart of study selection in systematic review and non-linear dose-response meta-analysis of BMI and all cause mortality

\begin{tabular}{|c|c|c|}
\hline & Never smokers & All participants \\
\hline No of studies (risk estimates) & $53(44)$ & $228(198)$ \\
\hline No of deaths & $>738144$ & $>3744722$ \\
\hline No of participants & $>9981558$ & 30233329 \\
\hline \multicolumn{3}{|c|}{ No of studies (risk estimates) by geographical location: } \\
\hline North America & $22(20)$ & $70(67)$ \\
\hline South America & $0(0)$ & $3(3)$ \\
\hline Europe & $18(11)$ & $96(69)$ \\
\hline Australia & $2(2)$ & $9(9)$ \\
\hline Asia & $11(11)$ & $49(49)$ \\
\hline Pacific & $0(0)$ & $1(1)$ \\
\hline \multicolumn{3}{|c|}{ No of studies (risk estimates) by study size: } \\
\hline$<1000$ & $2(2)$ & $15(12)$ \\
\hline $1000-<10000$ & $13(13)$ & $92(90)$ \\
\hline $10000-<100000$ & $20(18)$ & 89 (71) \\
\hline $100000-<1000000$ & $14(7)$ & $20(20)$ \\
\hline$\geq 1000000$ & $1(1)$ & $12(5)$ \\
\hline Missing & $3(3)$ & $0(0)$ \\
\hline Range of study size & $441-7436748$ & $162-12832637$ \\
\hline Mean, median & 243453,20346 & 152694,8876 \\
\hline \multicolumn{3}{|l|}{ Duration of follow-up: } \\
\hline Range of follow-up (years) & $3.9-35$ & $2-42$ \\
\hline Mean, median (years) & $14.2,12$ & $13.8,12$ \\
\hline
\end{tabular}

studies, cases, and participants, geographical location, study size, and mean or median duration of follow-up) of the studies included in the analysis of never smokers and among all participants. Some publications reported on or included data from more than one study (which were analysed as one combined dataset); one publication included data from nine studies, ${ }^{138}$ and another publication included eight cohort studies that were combined in one analysis, ${ }^{16}$ one publication reported results from six studies that were combined, ${ }^{95}$ five publications reported results from three studies that were

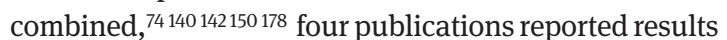
from two studies, ${ }^{163170} 189191$ which were included in the analysis. Four publications reported on men and women separately from the same two studies. ${ }^{30} 31131132$ Two duplicate publications were included only in subgroup analyses by sex ${ }^{229} 235$ as the main article provided only results for both sexes combined ${ }^{140}$ or because the duplicate publication had a longer follow-up. ${ }^{235}$ That publication was not used for the main analysis as it reported only on women, while the main publication reported on both men and women. ${ }^{166}$ One publication was included only in the analysis of African Americans ${ }^{237}$ as the main publication reported results from the full population. ${ }^{17}$

Ninety six studies were from Europe, 71 were from North America, three were from Latin or South America, 49 were from Asia, 10 were from Australia and New Zealand, and one was from the Pacific region (table B in appendix 2). Of the 198 risk estimates included in the non-linear dose-response analysis among all participants, $38(19.2 \%)$ had three categories of BMI, 61 (30.8\%) had four categories, 47 (23.7\%) had five categories, 17 (8.6\%) had six categories, 15 (7.6\%) had seven categories, four (2\%) had eight categories, 10 (5.1\%) had nine categories, and six (3\%) had 10 or more categories. Of the 44 risk estimates among never smokers, five $(11.4 \%)$ had three categories of BMI, five had four categories (11.4\%), 13 (29.6\%) had five categories, four (9\%) had six categories, three $(6.8 \%)$ had seven categories, four $(9 \%)$ had eight categories, five $(11.4 \%)$ had nine categories, and five (11.4\%) had 10 or more categories.

\section{BMI and mortality among never smokers and healthy never smokers}

We included 53 cohort studies (43 publications, 44 risk estimates) 16-22 2427303133363848495162779496 $107131132140159166178-180183185187188201221228230231234236238239$ with $>738144$ deaths and $>9976077$ participants in the analysis of never smokers. The summary relative risk for a 5 unit increase in BMI was 1.18 (95\% confidence interval 1.15 to $1.21 ; I^{2}=95 \%, P_{\text {heterogeneity }}<0.001$; fig $\mathrm{A}$ in appendix 3). There was no evidence of publication bias with Egger's test $(\mathrm{P}=0.67)$ or Begg's test $(\mathrm{P}=0.66)$ (fig $\mathrm{B}$ in appendix 3). There was evidence of non-linearity $(\mathrm{P}<0.001)$, and there was a J shaped association between BMI and mortality in never smokers with the lowest mortality observed with a BMI of 23-24 (fig 2). Table 2 shows the relative risk estimates from the non-linear dose-response analysis for selected BMI values, and these are derived from the non-linear figures. The association was similar in men and in women 

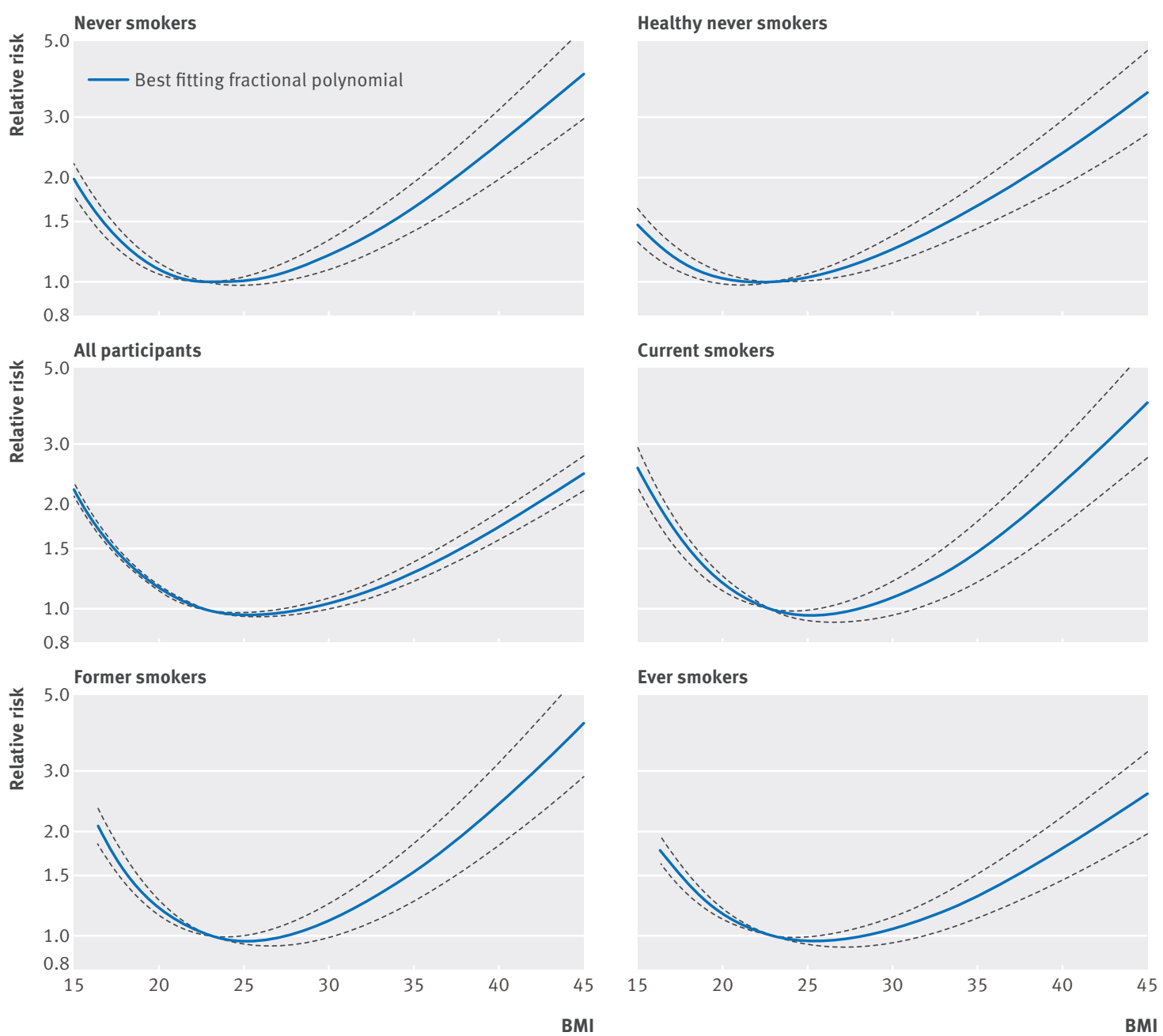

Fig 2 | Non-linear dose-response analysis of BMI and all cause mortality among never smokers, healthy never smokers, all participants, current, former, and ever smokers

(tables $\mathrm{C}$ and $\mathrm{D}$ in appendix 2). In an analysis of five studies of African American people who had never smoked, ${ }^{22249496237}$ the summary relative risk was 1.13 (1.10 to 1.17) for a 5 unit increase in BMI (fig $C$ in appendix 3), and there was evidence of a J shaped association $\left(\mathrm{P}_{\text {non-linearity }}<0.001\right.$; fig $\mathrm{D}$ in appendix 3$)$.

We included 26 cohort studies (25 publications, 25 risk estimates) 18192021222427303848517794131132140159178180183 185188228236238 with $>74464$ deaths among 727687 participants in the analysis of healthy never smokers (which in general excluded people with prevalent cancer, cardiovascular disease, and in some cases diabetes, and/or people with recent weight loss). The summary relative risk for a 5 unit increment in BMI was 1.21 (95\% confidence interval 1.18 to $1.25 ; \mathrm{I}^{2}=93 \%, \mathrm{P}_{\text {heterogeneity }}<0.001$; fig $\mathrm{E}$ in appendix 3, table 2). There was evidence of non-linearity $(\mathrm{P}<0.001)$, and there was a J shaped association between BMI and mortality in healthy people who had never smoked with the lowest mortality observed with a BMI of 22-23 (fig 2). Further restriction of the analysis to

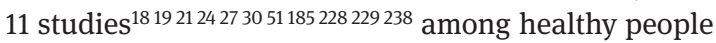
who had never smoked (88860 deaths, 1192443 participants), which also excluded early follow-up (from first year up to six years of follow-up) gave a summary relative risk of 1.27 (1.21 to $1.33 ; \mathrm{I}^{2}=89 \%, \mathrm{P}_{\text {heterogeneity }}<0.001$; fig $\mathrm{F}$ in appendix 3).

\section{BMI and all cause mortality (all participants)}

We included 228 cohort studies (191 publications, 198 risk estimates) $)^{16-2427-2932-5456-7678-115130-227}$ in the analysis of BMI and risk of all cause mortality and included a total of $>3744722$ deaths among 30233329 participants. The summary relative risk for a 5 unit increase in BMI was 1.05 ( $95 \%$ confidence interval 1.04 to $1.07 ; \mathrm{I}^{2}=97 \%, \mathrm{P}_{\text {heterogene- }}$ ity $<0.001$; fig $\mathrm{G}$ in appendix 3). There was indication of publication bias with Egger's test $(\mathrm{P}=0.002)$ but not with Begg's test $(\mathrm{P}=0.82)$, though the funnel plot indicated missing studies with positive results (fig $\mathrm{H}$ in appendix 3 ).

There was strong evidence of non-linearity $(\mathrm{P}<0.001)$, with a U shaped dose-response curve. The lowest mortality was observed with a BMI of 25 (fig 2, table 2).

\section{BMI and mortality in current, former, and ever} smokers

We included 22 studies (21 publications) $)^{17202227333849}$ 5177107131132149159166180183188230231233 (>270620 deaths, 3911812 participants), 17 studies (18 publications) ${ }^{1720}$ 222738495177107131132149159180183230231233 (>126786 deaths, 


\begin{tabular}{|c|c|c|c|c|c|c|}
\hline BMI & $\begin{array}{l}\text { Never smokers } \\
\left(n=44^{*}\right)\end{array}$ & $\begin{array}{l}\text { Healthy never } \\
\text { smokers }\left(n=26^{\star}\right)\end{array}$ & $\begin{array}{l}\text { All participants } \\
\left(n=198^{*}\right)\end{array}$ & $\begin{array}{l}\text { Current smokers } \\
\left(\mathrm{n}=18^{*}\right)\end{array}$ & $\begin{array}{l}\text { Former smokers } \\
\left(\mathrm{n}=15^{\star}\right)\end{array}$ & $\begin{array}{l}\text { Ever smokers } \\
\left(n=24^{*}\right)\end{array}$ \\
\hline 15 & $2.01(1.80$ to 2.24$)$ & $1.48(1.32$ to 1.65$)$ & 2.24 (2.15 to 2.34$)$ & 2.61 (2.27 to 2.99) & $-\dagger$ & $-\dagger$ \\
\hline 16 & 1.66 (1.51 to 1.83$)$ & 1.31 (1.19 to 1.44$)$ & 1.83 (1.77 to 1.91$)$ & $2.08(1.84$ to 2.34$)$ & 2.15 (1.91 to 2.42$)$ & 1.81 (1.66 to 1.97$)$ \\
\hline 17.5 & $1.35(1.25$ to 1.45$)$ & 1.15 (1.07 to 1.24$)$ & $1.47(1.43$ to 1.51$)$ & 1.61 (1.46 to 1.76$)$ & 1.68 (1.53 to 1.84$)$ & $1.50(1.40$ to 1.60$)$ \\
\hline 20 & $1.10(1.05$ to 1.14$)$ & 1.03 (0.99 to 1.07$)$ & 1.15 (1.13 to 1.17$)$ & 1.19 (1.13 to 1.25$)$ & $1.20(1.14$ to 1.26$)$ & $1.16(1.12$ to 1.20$)$ \\
\hline 22 & 1.01 (1.00 to 1.03$)$ & $1.00(0.99$ to 1.01$)$ & 1.03 (1.02 to 1.04$)$ & 1.04 (1.02 to 1.06$)$ & 1.04 (1.03 to 1.06$)$ & 1.04 (1.02 to 1.05$)$ \\
\hline 23 & 1.00 & 1.00 & 1.00 & 1.00 & 1.00 & 1.00 \\
\hline 24 & 1.00 (0.98 to 1.01) & 1.01 (1.00 to 1.02 ) & 0.98 (0.97 to 0.99) & 0.97 (0.96 to 0.99) & 0.98 (0.96 to 0.99$)$ & 0.98 (0.97 to 0.99) \\
\hline 25 & 1.01 (0.98 to 1.03$)$ & $1.03(1.00$ to 1.06$)$ & 0.97 (0.96 to 0.98$)$ & $0.96(0.93$ to 1.00$)$ & 0.97 (0.94 to 1.00$)$ & 0.97 (0.94 to 0.99) \\
\hline 27.5 & 1.07 (1.01 to 1.14) & 1.11 (1.05 to 1.18) & 0.98 (0.96 to 1.01) & 0.99 (0.92 to 1.06$)$ & 1.00 (0.93 to 1.08) & $0.98(0.93$ to 1.04$)$ \\
\hline 30 & 1.20 (1.09 to 1.32$)$ & 1.24 (1.14 to 1.36$)$ & 1.04 (1.00 to 1.08$)$ & 1.08 (0.96 to 1.21$)$ & 1.11 (0.99 to 1.24) & 1.05 (0.96 to 1.14$)$ \\
\hline 32.5 & 1.39 (1.22 to 1.58$)$ & $1.42(1.26$ to 1.60$)$ & 1.14 (1.09 to 1.20$)$ & 1.24 (1.06 to 1.45$)$ & 1.28 (1.10 to 1.49$)$ & 1.15 (1.02 to 1.30$)$ \\
\hline 35 & 1.65 (1.40 to 1.94$)$ & $1.66(1.43$ to 1.94$)$ & 1.29 (1.21 to 1.37$)$ & $1.48(1.21$ to 1.80$)$ & 1.54 (1.27 to 1.87$)$ & 1.31 (1.13 to 1.52$)$ \\
\hline 37.5 & 2.02 (1.66 to 2.46$)$ & 1.98 (1.64 to 2.38$)$ & $1.49(1.37$ to 1.61$)$ & 1.82 (1.43 to 2.32$)$ & 1.91 (1.51 to 2.41$)$ & 1.51 (1.27 to 1.81$)$ \\
\hline 40 & 2.50 (1.98 to 3.15$)$ & 2.37 (1.91 to 2.95$)$ & 1.74 (1.59 to 1.91$)$ & 2.32 (1.74 to 3.08$)$ & 2.44 (1.85 to 3.20$)$ & $1.79(1.45$ to 2.21$)$ \\
\hline 42.5 & $3.16(2.42$ to 4.12$)$ & $2.88(2.24$ to 3.69$)$ & 2.07 (1.86 to 2.30$)$ & $3.03(2.18$ to 4.20$)$ & $3.15(2.30$ to 4.32$)$ & 2.14 (1.68 to 2.73$)$ \\
\hline 45 & $4.02(2.98$ to 5.43$)$ & $3.54(2.67$ to 4.69$)$ & $2.49(2.22$ to 2.81$)$ & 4.01 (2.77 to 5.81) & $4.18(2.92$ to 5.97$)$ & 2.61 (1.99 to 3.43) \\
\hline
\end{tabular}

*No of risk estimates.

†Lowest value was BMI 16.25

$>1523435$ participants), and 24 studies (25 publications) ${ }^{17-20} 222733363849517794107131132159180183201221$ 230231232239 (>696134 deaths, 6616140 participants) studies in the analyses of current, former, and ever smokers, respectively. There was strong evidence of non-linearity in all analyses $(\mathrm{P}<0.001$ for all), and there was a U shaped curve for the association between BMI and mortality among current, former, and ever smokers (fig 2, table 2).

\section{Subgroup and sensitivity analyses}

In the analysis of never smokers there was indication of heterogeneity $(\mathrm{P}=0.02)$ when we stratified studies by median or mean duration of follow-up (table $\mathrm{C}$ in appendix 2), and the summary relative risks for a 5 unit increment in BMI were 1.21 (95\% confidence interval 1.14 to $1.28 ; n=1), 1.11$ ( 0.94 to $1.30 ; n=11), 1.18$ (1.14 to $1.22 ; n=18$ ), 1.24 (1.09 to $1.40 ; n=4$ ), 1.30 (1.19 to 1.42 ; $\mathrm{n}=2$ ), and 1.25 (1.20 to $1.30 ; \mathrm{n}=7$ ) for $<5,5-<10,10-<15$, $15-<20,20-<25$ and $\geq 25$ years of follow-up, respectively. In the non-linear dose-response analysis restricted to studies with $\geq 20$ or $\geq 25$ years of follow-up, there was no increased risk at the low BMI range down to a BMI of 20, while risk increased slightly even within the high normal range (BMI of $24-<25$ ) but was more pronounced in the overweight, obese, and severely obese $\mathrm{BMI}$ ranges (table $\mathrm{E}$ in appendix 2, fig 3 ). In the analysis of all participants there was also significant heterogeneity $(\mathrm{P}<0.001)$ when we stratified studies by median or mean duration of follow-up (table B in appendix 2), and the summary relative risks for a 5 unit increment in BMI were 0.90 ( 0.83 to $0.97 ; n=15)$, 1.00 (0.96 to $1.04 ; n=53), 1.07$ (1.05 to $1.08 ; n=66), 1.09$ (1.05 to $1.13 ; n=27), 1.12$ (1.08 to $1.17 ; n=15)$, and 1.15 (1.11 to 1.19; $\mathrm{n}=22$ ) for $<5,5-<10,10-<15,15-<20,20-<25$, and $\geq 25$ years of follow-up, respectively. In the non-linear dose-response analysis, the shape of the dose-response curve changed gradually from a U shape to a J shape with increasing durations of follow-up (table $G$ in appendix 2, fig 4).
There was no heterogeneity in the analyses among never smokers when we stratified by sex, and, although there was heterogeneity when we stratified analyses of all participants by sex, this seemed to be due to no association among the studies of men and women combined, and when analysis was restricted to studies in either men or women there was no heterogeneity (tables C, D, and F in appendix 2, fig I in appendix 3). Although there was evidence of heterogeneity by geographical location in the linear dose-response analysis of all participants $(\mathrm{P}=0.04)$, with a significant positive association observed only for Europe and North America (table F in appendix 2), there was no heterogeneity by geographical location in never smokers $(\mathrm{P}=0.91)$ and positive associations were observed in European, North American, Australian, and Asian studies (table $\mathrm{C}$ in appendix 2), although slight variations in the risk estimates from the non-linear dose-response analyses were observed (table $\mathrm{H}$ in appendix 2, fig J in appendix 3). There was evidence of heterogeneity between studies when we stratified by study quality scores in the analysis of all participants $(\mathrm{P}=0.03)$, with a significant association among studies with high study quality scores but not among the studies with medium study quality scores (table F in appendix 2). The non-linearity was also more pronounced among the studies with medium study quality compared with the studies of high study quality (table I in appendix 2, figs $\mathrm{K}$ and $\mathrm{L}$ in appendix 3). There was, however, no heterogeneity by study quality scores in the subgroup analyses of never smokers (table $\mathrm{C}$ in appendix 2, figs $\mathrm{M}$ and $\mathrm{N}$ in appendix 3). There was evidence of heterogeneity when we stratified studies by the number of deaths in the analysis of all participants $(\mathrm{P}<0.001)$, with a stronger association among studies with a larger number of deaths compared with studies with a smaller number of deaths (table $\mathrm{F}$ in appendix 2), but this was not observed in never smokers (table $\mathrm{C}$ in appendix 2). 
Fig 3 | Non-linear doseresponse analysis of BMI and all cause mortality in never smokers stratified by duration of follow-up
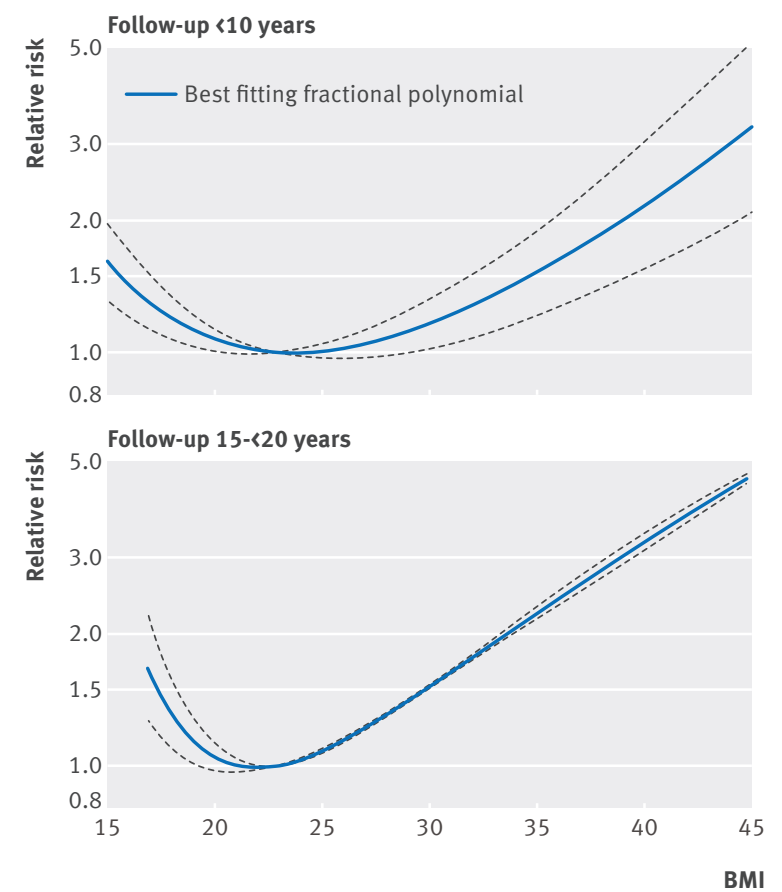

Follow-up 10-<15 years

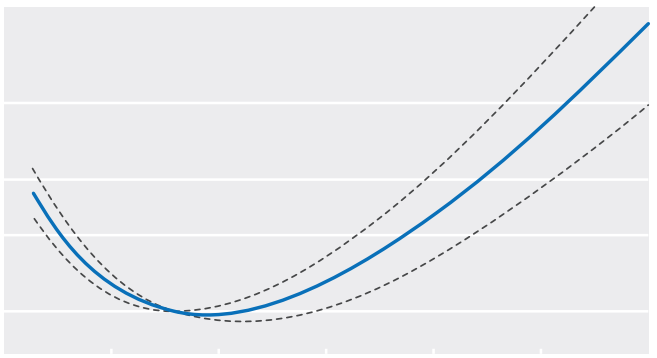

Follow-up $\geq 20$ years

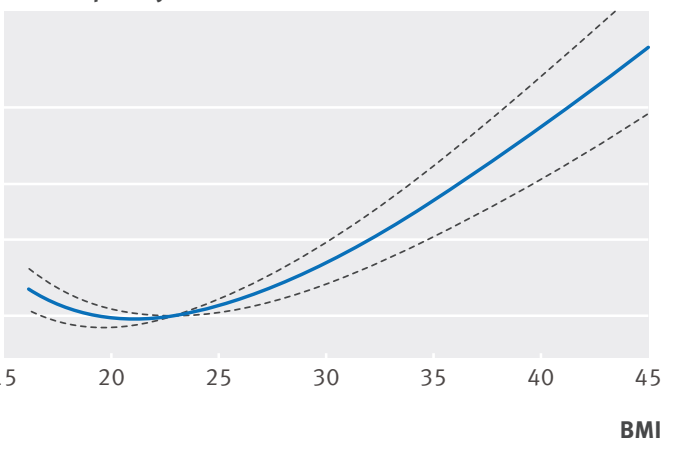

Follow-up 5-<10 years
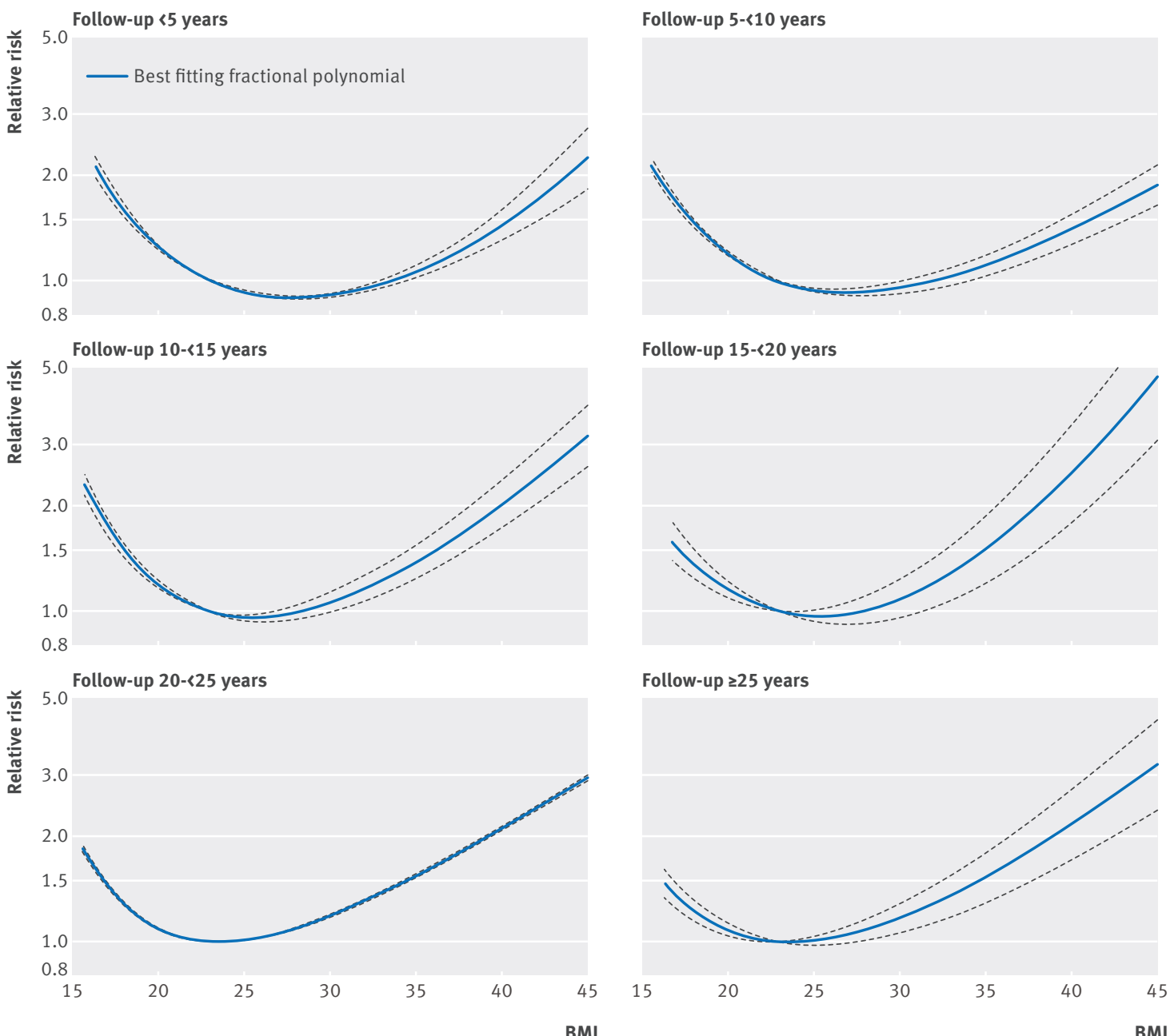

Follow-up 15-<20 years

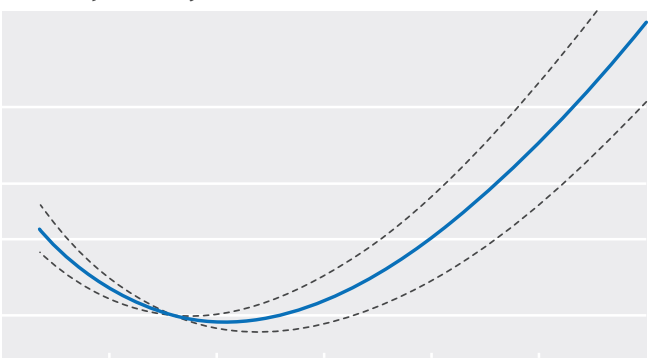

Follow-up $\geq 25$ years

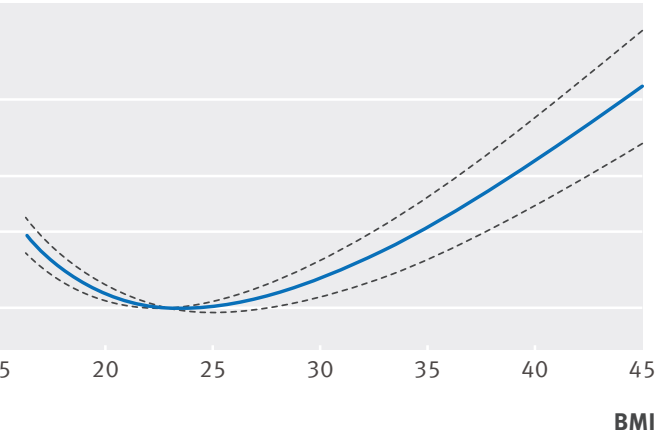

Fig 4 | Non-linear doseresponse analysis of BMI and all cause mortality in all participants stratified by duration of follow-up 
The positive association between BMI and all cause mortality among never smokers persisted in subgroup analyses defined by sex, assessment of anthropometric measures, geographical location, number of deaths, and adjustment for confounding factors including age, education, alcohol, physical activity, height, dietary pattern, and intake of fat, fruit, and vegetables. There was little evidence of heterogeneity between any of these subgroups with meta-regression analyses (table $\mathrm{C}$ in appendix 2). We observed no association among the few studies that adjusted for potential intermediate factors (diabetes, hypertension, cholesterol). In general, heterogeneity was high in most of the subgroup analyses.

In the analysis of all participants there was no evidence of heterogeneity when we stratified studies by adjustment for age, education, socioeconomic status, alcohol, smoking status, pack years, years since quitting, physical activity, height, dietary pattern, fat intake, or fruit and vegetable intake. There was heterogeneity among studies when we stratified by adjustment for number of cigarettes smoked a day $(\mathrm{P}<0.001)$, with a stronger association among studies with such adjustment compared with studies without such adjustment (table $\mathrm{F}$ in appendix 2). There was also indication of a stronger association among studies with adjustment for years since quitting compared with studies without such adjustment, though the test for heterogeneity between subgroups was not significant.

When we stratified studies by potential intermediates, there was heterogeneity by whether studies adjusted for diabetes, with no association among studies with such adjustment (table $\mathrm{F}$ in appendix 2). Although the test for heterogeneity was not significant, there was also no association among studies with adjustment for systolic blood pressure and hypertension. There was also heterogeneity by adjustment for prevalent coronary heart disease $(\mathrm{P}=0.003)$, stroke $(\mathrm{P}=0.07)$, and prevalent cancer $(\mathrm{P}=0.03)$, with no association among studies with such adjustment (table F in appendix 2). Although the test for heterogeneity between subgroups was not significant, the association between BMI and mortality was stronger among studies that had adjusted for the most important confounding factors (age, smoking, alcohol, physical activity) but that did not adjust for intermediate factors or prevalent disease. These associations were further strengthened among studies with longer duration of follow-up (table $\mathrm{C}$ and $\mathrm{F}$ in appendix 2).

In a further subgroup analysis among never smokers the association between BMI and all cause mortality was considerably stronger among people aged $<65$ (summary relative risk 1.27, 95\% confidence interval 1.22 to $\left.1.34 ; \mathrm{I}^{2}=91 \%, \mathrm{P}_{\text {heterogeneity }}<0.001, \mathrm{n}=14\right)$ than among people aged $\geq 65$ (1.04, 1.01 to $1.07 ; \mathrm{I}^{2}=72 \%$, $\mathrm{P}_{\text {heterogene- }}$ ity $=0.004, n=6)$, with significant heterogeneity between subgroups $(\mathrm{P}<0.001$; fig $\mathrm{O}$ in appendix 3$)$. The association was also considerably stronger among younger people in the non-linear dose-response analysis (figs $\mathrm{P}$ and $\mathrm{Q}$ in appendix 3, table J in appendix 2).

In sensitivity analyses that excluded one study at a time there was minimal variation in the summary relative risk for never smokers (table $\mathrm{K}$ in appendix 2) and all participants (table L in appendix 2). In a further sensitivity analysis that excluded studies in which the BMI in the reference category was $<18.5$ or $<20.0$, the summary relative risks were 1.19 (95\% confidence interval 1.17 to $\left.1.22 ; \mathrm{I}^{2}=92 \%, \mathrm{P}_{\text {heterogeneity }}<0.001, \mathrm{n}=43\right)$ and 1.19 (1.16 to $1.22 ; \mathrm{I}^{2}=92 \%, \mathrm{P}_{\text {heterogeneity }}<0.001, \mathrm{n}=41$ ), respectively, per 5 BMI units among never smokers, and 1.07 (1.06 to $1.08 ; \mathrm{I}^{2}=96 \%, \mathrm{P}_{\text {heterogeneity }}<0.001, \mathrm{n}=178$ ) and 1.07 (1.06 to $1.08 ; \mathrm{I}^{2}=96 \%, \mathrm{P}_{\text {heterogeneity }}<0.001, \mathrm{n}=172$ ), respectively, among all participants.

\section{Discussion}

This meta-analysis of 230 cohort studies with $>3.74$ million deaths among $>30.3$ million participants provides further evidence that adiposity as measured by BMI increases the risk of premature mortality. There is also some increase in risk in underweight people, but this might at least partly be a non-causal association. In the analysis of all participants the lowest mortality was observed in those with a BMI of around 25. In subgroup analyses, however, the lowest mortality was observed in the BMI range of 23-24 among never smokers, 22-23 among healthy never smokers, and 20-22 among studies of never smokers with longer durations of follow-up ( $\geq 20$ and $\geq 25$ years).

The analysis of all participants needs to be interpreted carefully as there is a greater possibility of confounding by smoking and confounding from prediagnostic weight loss associated with disease. Some studies might have over-adjusted the analysis by including some intermediate factors such as diabetes, blood pressure, hypertension, and serum cholesterol in the multivariate models. In addition, there was heterogeneity by study quality scores, with more evidence of a U shaped association among moderate quality than among high quality studies. There was some evidence of small study bias, such as publication bias, in the analysis of all participants, although this was not observed in the analysis of never smokers. If anything, however, the funnel plot indicated the presence of missing studies with positive results, suggesting a possible underestimation of the association in the analysis of all participants.

The shape of the dose-response curve differed greatly when we included all people (no exclusions) and when we restricted the analysis to never smokers and healthy never smokers as there was more of a U shaped dose-response relation in the analysis of all participants and a J shaped dose-response relation among never smokers. This is consistent with a pooled analysis from the National Cancer Institute (NCI) Cohort Consortium ${ }^{14}$ and partly consistent with the results of the Prospective Studies Collaboration, ${ }^{2}$ in which the increased risk in participants with a BMI $<20$ was much more pronounced in current smokers than in never smokers. In this analysis of all people and former, current, and ever smokers there was a slight inverse association towards the overweight range compared with a BMI of 23 and weaker relative risks in the overweight and obese range than among never smokers. The relative risks were also more similar to that observed in the meta-analysis by Flegal and colleagues ${ }^{26}$ in the 
unrestricted analysis, in studies with a shorter duration of follow-up, and among smokers, subgroups that could be particularly prone to confounding by smoking and confounding from existing illness. When we restricted the analysis to never smokers there was evidence of increased mortality in the overweight range with more substantial increases in risk in the obese and morbidly obese range. Furthermore, when the analysis was restricted to studies with a longer duration of follow-up, which would be less influenced by confounding by pre-diagnostic weight loss, the increased risk among people with a BMI of 20 disappeared and was substantially attenuated in the underweight never smokers, while in all participants the inverse association in the overweight range was reversed and in the direction of increased risk. Thus, the increased risk observed with a BMI of 20 in the analysis of all participants and never smokers and the lower risk in overweight people in the analysis of all participants is likely to be caused by confounding by smoking and prediagnostic weight loss.

We also found significant heterogeneity when we stratified studies by study quality scores in the analysis of all participants, with no significant association among studies with moderate scores compared with a stronger association in studies with higher scores in the linear dose-response analysis. In the non-linear dose-response analysis, the lowest risk was observed in the overweight range at a BMI of 27.5 in the studies with medium quality scores, while the lowest risk was observed at a BMI of 24-25 in the studies with the highest quality scores. This finding provides further support that issues related to the study quality could have contributed to the slight inverse association at the high end of the normal weight category and in the overweight category in the analysis of all participants. Finally, we also found significant heterogeneity when we stratified studies in never smokers by baseline age, with a much stronger association among people aged $<65$ than among those aged $\geq 65$, and this is at least partly consistent with the data from the NCI Cohort Consortium. ${ }^{14}$

\section{Results in context}

The results of our analysis of never smokers and healthy never smokers are in line with the results from the NCI Cohort Consortium, which reported hazard ratios of $1.09,1.19,1.44,1.88$, and 2.51 in the BMI ranges 25-27.4, 27.5-29.9, 30.0-34.9, 35.0-39.9, and 40-49.9 for women and $1.06,1.21,1.44,2.06$ and 2.93 for men in the respective BMI categories compared with 22.5-24.9,14 while we found summary relative risks of 1.11, 1.24, 1.42, 1.98 and 3.54 for BMI values of 27.5, 30, 32.5, 37.5, and 45 compared with a BMI of 23. The somewhat weaker association in the linear dose-response analysis in the current analysis (summary relative risk 1.18 (95\% confidence interval 1.15 to 1.22) per $5 \mathrm{BMI}$ units increase for never smokers, 1.21 (1.18 to 1.25) for healthy never smokers, and 1.27 (1.21 to 1.34 ) for healthy never smokers with exclusion of early follow-up) compared with the NCI Cohort Consortium (hazard ratio 1.31 (95\% confidence interval 1.29 to 1.33 ) for healthy never smokers with exclusion of the first year of follow-up in the BMI range
25-49.9) $)^{14}$ and the Prospective Studies Collaboration (1.32 (1.28 to 1.36) for never smokers with exclusion of first five years of follow-up) ${ }^{2}$ might be because of differences in the number of studies and participants included but might also be because these pooled analyses had access to the original data from each study and restricted the linear dose-response analysis in two ranges, 15-25 and 25-50. In our linear dose-response analysis we used the reference category as reported in each publication, which meant the BMI range would go lower as most of the studies had midpoints for the reference category between BMI 20 and 22, the part of the curve where the dose-response relation was less steep.

\section{Limitations of study}

Our meta-analysis has some limitations that need to be mentioned. As a meta-analysis of observational studies, confounding by unmeasured or imperfectly measured risk factors could have influenced the results. Smoking is a strong risk factor for premature mortality and several specific causes of death. ${ }^{116117}$ A recent comprehensive analysis in the Million Women's Study reported increased risk from 23 specific causes of death among current smokers compared with never smokers, ${ }^{116}$ while a pooled analysis of five American cohort studies with more than a million participants reported increased risk of 35 and 41 specific causes of death in men and women, respectively. ${ }^{117}$ At the same time smoking is associated with reduced body weight, leading to a lower BMI. ${ }^{118240}$ The adverse effects of smoking are so strong that conventional multivariate adjustment is not sufficient to remove the confounding effects of smoking on the relation between BMI and several cancers (mouth, oesophagus, larynx, lung, and possibly pancreas, gallbladder, and liver) 5241-243 $^{2}$ and several specific causes of death (most notably chronic obstructive pulmonary disease and pneumonia),,2244 and this is also likely to be the case for all cause mortality. Further in support of this argument is the observation that the conditions most strongly associated with smoking (cancers of the lung and upper aerodigestive tract and other respiratory diseases ${ }^{116117}$ ) are also the conditions for which the BMI-disease association shows the largest difference in risk estimates when analyses are restricted to never smokers. ${ }^{8241243}$ Therefore it is necessary to restrict the analysis to never smokers to obtain valid results. The differences in the shape of the dose-response relation between BMI and mortality in smokers and never smokers as well as the stronger risk estimates among studies with adjustment for smoking (smoking status, cigarettes per day, time since quitting) we observed provide further support that smoking is a powerful confounder of the relation between adiposity and mortality.

Though other confounding factors could have influenced the results, in the analysis of never smokers the results persisted among studies that adjusted for age, education, alcohol, physical activity, height, dietary pattern, and intake of fat and fruit and vegetables, although few studies adjusted for dietary factors, suggesting that at least these confounders do not explain the association between BMI and mortality. In addition, it is possible that the increased risk observed in the underweight BMI range 
could be attenuated by physical activity or a generally healthy lifestyle, ${ }^{14159}$ but we were not able to investigate potential interactions between BMI and physical activity or dietary factors in relation to all cause mortality as few studies reported such results. Although BMI is an imperfect measure of body fatness as it does not distinguish between lean mass and fat mass, in most people it is highly correlated with measures of body fat ${ }^{245246}$ and has been shown to be predictive of several chronic diseases. ${ }^{812247}$ BMI might be a less reliable marker of adiposity in the elderly as the prevalence of chronic disease (and associated weight loss) increases with age and because of loss of muscle mass from the ageing process. ${ }^{248}$ This might explain the weaker association observed between BMI and mortality in older than in younger people. These findings are also consistent with the results of several previous studies, 141794107 though because of higher death rates absolute risks are much greater in older people. ${ }^{249} \mathrm{~A}$ pooled analysis ${ }^{250}$ and a meta-analysis ${ }^{251}$ and the European Prospective Investigation into Cancer and Nutrition study ${ }^{20}$ reported linear increases in risk of mortality with greater waist circumference and waist to hip ratio, even among older people ${ }^{20}$ and within the normal BMI range, ${ }^{20250}$ thus incorporating waist measures might have additional clinical relevance for risk assessment.

The results were slightly stronger when we restricted the analysis to healthy never smokers (without prevalent disease at baseline), but the increased risk in the participants with a low BMI persisted in these analyses. Nevertheless, residual confounding is still possible as an explanation for the increased risk with a low BMI because most studies excluded only participants with prevalent cardiovascular disease and cancer, and only five of the 26 studies additionally excluded people with respiratory disease. In the NCI Cohort Consortium the effect of exclusion of participants with prevalent disease on the association between BMI and mortality was more pronounced in men and for heart disease rather than for cancer, stroke, or respiratory disease. ${ }^{14}$ Confounding by undiagnosed disease, however, is still a possibility as weight loss can precede the diagnosis of some neurological and respiratory diseases by as much as 10-15 years $^{234252253}$ and because most of the studies excluded only the first one, two, or three years of follow-up. In a further subgroup analysis stratified by duration of follow-up we found that the increased risk among people with a BMI of 20 disappeared and in underweight people was substantially attenuated and the increased risk in overweight and obese people was strengthened among studies with $\geq 20$ or $\geq 25$ years of follow-up. This is in line with the results from the NCI Cohort Consortium, where the increased risk among people with a BMI between 18.5 and 19.9 disappeared and that of underweight people was greatly reduced in the subgroup with 15 or more years of follow-up, ${ }^{14}$ while the positive association with higher BMI was strengthened with a longer duration of follow-up. This suggests that weight loss from prediagnostic disease could explain the increased risk we observed in the low-normal weight and underweight BMI ranges. However, another potential explanation might be if people gained weight over time, as some underweight people might become normal weight and obese people become even more obese over the follow-up period. It has been shown that weight loss associated with disease before baseline is associated with increased risk of mortality ${ }^{254}$ and that in people with stable BMI there was a linear increase in risk of mortality with higher BMI, while in those who previously experienced weight loss (likely because of chronic illness) there was a more U shaped association between BMI and mortality. ${ }^{255}$ Any further large scale cohort studies or pooled analyses should investigate these issues further by incorporating repeated anthropometric assessments during follow-up.

Another limitation is that the number of studies that conducted analyses stratified by smoking status was small compared with the total number of studies (53 out of 228 studies). However, many of the studies that provided results for never smokers were very large and accounted for $68 \%$ of the total participants and $63 \%$ of the total deaths in this meta-analysis (2372930 deaths and 20542502 participants out of a total of $>3744722$ deaths among 30233329 participants), thus most likely the results for never smokers would not have been dramatically different if all studies had reported such data. The analyses of healthy never smokers and healthy never smokers with exclusion of early follow-up had a more limited number of studies included (26 and 11, respectively) and might therefore be less representative of all the studies included but still included a larger number of deaths and participants among healthy never smokers than previous pooled analyses. ${ }^{214}$

Measurement errors in the assessment of height and weight could have influenced the results. Most validation studies have found high correlations between self reported and measured height and weight, ${ }^{256-258}$ though some under-reporting of weight and over-reporting of height can occur. When studies were stratified by whether weight and height was measured or self reported the summary relative risk was slightly weaker among studies that used measured data compared with studies that used self reported data, though there was no significant heterogeneity between these subgroups. Height, weight, smoking status, and other covariates were measured only at baseline and changes in these factors could have occurred during follow-up, but we were not able to take such changes into account because most studies lacked such data.

One final limitation is that because of resource constraints we included only English language publications. We assumed that most of the large scale and well conducted cohort studies of importance will have been published in English language journals. Given the large number of studies included in the present analysis any additional studies published in non-English journals would have to be very large and/or have a substantially different result than the present cohort studies to change any of the results meaningfully, but we consider this possibility less likely.

\section{Strengths of the study}

Our meta-analysis has several strengths. As we used fractional polynomial models for the analyses we were able to 
include a larger number of studies with a much larger number of deaths and participants than previously with more than 3.74 million deaths among 30.2 million participants in 228 studies in the analysis of all participants, which is almost 14 times the number of deaths and $>10$ times the number of participants and more than twice the number of studies compared with the meta-analysis by Flegal and colleagues. ${ }^{26}$ In the analysis of never smokers, there were $>738000$ deaths among $>9.97$ million participants, among healthy never smokers there were $>74464$ deaths among 727687 participants, and among healthy never smokers with exclusion of early follow-up there were 88860 deaths among 1192443 participants, which compares favourably with the 35369 deaths and 687590 healthy never smokers (first year of follow-up excluded) in the NCI Cohort Consortium. ${ }^{14}$ The fractional polynomial method has the advantage that studies are not required to use the exact same cut-off points when analysing BMI, thus we were able to include important studies that were previously excluded. ${ }^{26}$ We conducted analyses stratified by smoking status, prevalent disease, and exclusion of early follow-up to investigate the potential impact of residual confounding from smoking and prevalent and undiagnosed disease. We observed important differences between studies among never smokers and those among former, current, and ever smokers with a more J shaped curve for never smokers, while there was a U shaped curve among smokers, suggesting that smoking might have influenced previous results that showed inverse associations in the overweight range. In addition, we stratified the analyses by duration of follow-up to clarify the potential influence of confounding by illness from prediagnostic weight loss. We found large differences in the shape of the dose-response relation with different durations of follow-up, with more $U$ shaped associations with shorter follow-up and J shaped associations with longer follow-up. We conducted several subgroup analyses by study characteristics, study quality scores, and adjustment for confounding and mediating factors, and the findings persisted in sensitivity analyses excluding one study at a time, suggesting that no individual study explained the results.

\section{Mechanisms}

Several potential mechanisms could explain an association between BMI and risk of premature mortality. Adiposity is an established risk factor for cardiovascular disease (coronary heart disease, stroke) and increases risk through increased cholesterol and triglyceride concentrations, raised blood pressure, low grade inflammation, and insulin resistance. ${ }^{2}$ Overweight and obesity is the strongest established risk factor for type 2 diabetes, ${ }^{3}$ which is associated with a two-threefold increase in risk of mortality. ${ }^{259}$ Adiposity is an established risk factor for at least 10 different cancers, including cancers of the oesophagus (adenocarcinoma), liver, gallbladder, colorectum, pancreas, kidney, prostate (advanced cancer only), breast (postmenopausal), endometrium, and ovaries, 4678 and there is some evidence to suggest an association with several other cancers, including thyroid cancer, leukaemia, multiple myeloma, and lymphomas ${ }^{8}$ as well as with worse survival after cancer diagnosis. ${ }^{260261}$ A wide range of mechanisms could explain the association with these cancers, including hormonal effects of adipose tissue, insulin resistance, inflammation, effects on predisposing conditions such as gastro-oesophageal reflux disease, ${ }^{262}$ Barrett's oesophagus, ${ }^{263}$ gallbladder disease, ${ }^{9}$ and colorectal adenomas, ${ }^{264}$ and through effects on the immune system. ${ }^{265}$ There is also evidence for an association between adiposity and a wide range of other chronic disease outcomes, which can also lead to complications and death. ${ }^{10-13}$ On the other hand, there is some indication that being underweight can increase the risk of chronic pulmonary disease and other respiratory diseases, 21820266 though reverse causality and confounding might at least partly explain these findings as weight loss can be an indicator of progressive chronic obstructive pulmonary disease and because smoking is so strongly related to these conditions. ${ }^{267}$ For several outcomes, including coronary heart disease, hypertension, hypercholesterolemia, type 2 diabetes, gallstones, gout, colon, and endometrial cancer, there is evidence of increased risk even within the high end of the normal BMI range, ${ }^{7910} 247$ and this might explain the slightly increased risk of all cause mortality observed among never smokers even at a BMI of 24-25 in the current meta-analysis, when restricted to studies with $\geq 20$ or $\geq 25$ years follow-up.

\section{Policy implications and future research}

The current analysis provides strong evidence that overweight and obesity increases the risk of all cause mortality and therefore reinforces previous concerns regarding the adverse health effects of excess weight. Previous recommendations regarding body weight for prevention of chronic diseases such as cancer and cardiovascular disease have recommended a BMI within the normal range of 18.5-24.9, as defined by the WHO. ${ }^{120}$ Some recommendations stated that it would be best to stay as lean as possible within the normal range as there is evidence of increased risk of cardiovascular disease, cancer, diabetes, and some other diseases even within the high normal range (22-24.9).4910 247 The current results support these recommendations but suggest that the lowest mortality is observed with a BMI of 22-24 (depending on whether prevalent disease is excluded or not), although we cannot entirely rule out the possibility that this might be a slight overestimate if the increased risk observed among people with a BMI of 20 is non-causal, as indicated by the studies with longer durations of follow-up. Any further studies should investigate in more detail the association between BMI and other adiposity measures and specific causes of death, including less common diseases contributing to all cause mortality, and take into account the important methodological issues that have been highlighted in the current meta-analysis.

\section{Conclusions}

In conclusion, both overweight and obesity increases the risk of all cause mortality with a J shaped dose-response relation, and the nadir of the dose-response curve seems to be in the BMI range of 23-24 among never smokers and 
22-23 among healthy never smokers. With longer duration of follow-up the nadir of the dose-response curve is in the BMI range of 20-22. There is some evidence of increased mortality in underweight people, but we cannot exclude the possibility that this could partly be because of residual confounding from prediagnostic disease. Lack of exclusion of ever smokers, people with prevalent disease, and early follow-up and inclusion of studies with lower study quality could bias the associations between BMI and mortality towards a more U shaped association.

We authors thank Darren C Greenwood (Biostatistics Unit, Centre for Epidemiology and Biostatistics, University of Leeds, Leeds) for the Stata code for the non-linear dose-response analysis, and Anders Engeland (Department of Global Public Health, University of Bergen) for clarification of the studies included in the Norwegian Health Survey study.

Contributors: DA, TN, and LJV conceived and designed the study. All authors acquired, analysed, or interpreted data and critically revised the manuscript for important intellectual content. MP checked the data extraction. DA did the statistical analysis and drafted the manuscript. DA and LJV obtained funding. LJV supervised the study. DA had full access to all of the data and takes responsibility for the integrity of the data and the accuracy of the data analysis. DA and AS are guarantors.

Funding: This project was funded by the liaison committee between the Central Norway Regional Health Authority (RHA) and the Norwegian University of Science and Technology (NTNU), and Imperial College National Institute of Health Research (NIHR) Biomedical Research Centre (BRC). The funders had no role in the study design, data collection, data analysis and interpretation, writing of the report, or the decision to submit the article for publication.

Competing interests: All authors have completed the ICMJE uniform disclosure form at http://www.icmje.org/coi_disclosure.pdf and declare: no support from any organisation for the submitted work; no financial relationships with any organisation that might have an interest in the submitted work in the previous three years; no other relationships or activities that could appear to have influenced the submitted work.

Ethical approval: Not required.

Transparency: The lead author affirms that the manuscript is an honest, accurate, and transparent account of the study being reported; that no important aspects of the study have been omitted; and that any discrepancies from the study as planned have been disclosed.

Data sharing: No additional data available.

This is an Open Access article distributed in accordance with the Creative Commons Attribution Non Commercial (CC BY-NC 3.0) license, which permits others to distribute, remix, adapt, build upon this work non-commercially, and license their derivative works on different terms, provided the original work is properly cited and the use is noncommercial. See: http://creativecommons.org/licenses/by-nc/3.0/.

$1 \mathrm{Ng}$ M, Fleming T, Robinson M, et al. Global, regional, and national prevalence of overweight and obesity in children and adults during 1980-2013: a systematic analysis for the Global Burden of Disease Study 2013. Lancet 2014:384:766-81. doi:10.1016/

S0140-6736(14)60460-8

2 Whitlock G, Lewington S, Sherliker P, et al. Prospective Studies Collaboration. Body-mass index and cause-specific mortality in 900 000 adults: collaborative analyses of 57 prospective studies. Lancet 2009;373:1083-96. doi:10.1016/S0140-6736(09)60318-4.

3 Abdullah A, Peeters A, de Courten M, Stoelwinder J. The magnitude of association between overweight and obesity and the risk of diabetes: a meta-analysis of prospective cohort studies. Diabetes Res Clin Pract 2010;89:309-19. doi:10.1016/j.diabres.2010.04.012.

4 World Cancer Research Fund/American Insitute for Cancer Research. Food, Nutrition, Physical Activity and the Prevention of Cancer: a Global Perspective.AICR, 2007.

5 Aune D, Greenwood DC, Chan DS, et al. Body mass index, abdominal fatness and pancreatic cancer risk: a systematic review and non-linear dose-response meta-analysis of prospective studies. Ann Oncol 2012;23:843-52. doi:10.1093/annonc/mdr398.

6 Aune D Navarro Rosenblatt DA Chan DS, et al. Anthropometric factors and ovarian cancer risk: a systematic review and nonlinear dose-response meta-analysis of prospective studies. Int / Cancer 2015;136:1888-98. doi:10.1002/ijc.29207.

7 Aune D, Navarro Rosenblatt DA, Chan DS, et al. Anthropometric factors and endometrial cancer risk: a systematic review and dose-response meta-analysis of prospective studies. Ann Oncol 2015;26:1635-48. doi:10.1093/annonc/mdv142.
8 Renehan AG, Tyson M, Egger M, Heller RF, Zwahlen M. Body-mass index and incidence of cancer: a systematic review and meta-analysis of prospective observational studies. Lancet 2008;371:569-78. doi:10.1016/S0140-6736(08)60269-X.

9 Aune D, Norat T, Vatten LJ. Body mass index, abdominal fatness and the risk of gallbladder disease. Eur J Epidemiol 2015;30:1009-19. doi:10.1007/s10654-015-0081-y.

10 Aune D, Norat T, Vatten LJ. Body mass index and the risk of gout: a systematic review and dose-response meta-analysis of prospective studies. Eur J Nutr 2014:53:1591-601. doi:10.1007/ s00394-014-0766-0.

11 Guh DP, Zhang W, Bansback N, Amarsi Z, Birmingham CL, Anis AH. The incidence of co-morbidities related to obesity and overweight: a systematic review and meta-analysis. BMC Public Health 2009;9:88. doi:10.1186/1471-2458-9-88.

12 Reeves GK, Balkwill A, Cairns BJ, Green J, Beral V. Million Women Study Collaborators. Hospital admissions in relation to body mass index in UK women: a prospective cohort study. BMC Med 2014;12:45. doi:10.1186/1741-7015-12-45.

13 Patterson RE, Frank LL, Kristal AR, White E. A comprehensive examination of health conditions associated with obesity in older adults. Am J Prev Med 2004;27:385-90. doi:10.1016/j.amepre.2004.08.001.

14 Berrington de Gonzalez A, Hartge P, Cerhan JR, et al. Body-mass index and mortality among 1.46 million white adults. N Engl J Med 2010;363:2211-9. doi:10.1056/NEJMoa1000367.

15 Calle EE, Thun MJ, Petrelli JM, Rodriguez C, Heath CW Jr. Body-mass index and mortality in a prospective cohort of U.S. adults. N Engl I Med 1999;341:1097-105. doi:10.1056/NEJM199910073411501.

16 Engeland A, Bjørge T, Selmer RM, Tverdal A. Height and body mass index in relation to total mortality. Epidemiology 2003;14:293-9. doi:10.1097/01.EDE.0000047889.30616.73.

17 Adams KF, Schatzkin A, Harris TB, et al. Overweight, obesity, and mortality in a large prospective cohort of persons 50 to 71 years old. $N$ Engl J Med 2006;355:763-78. doi:10.1056/NEJMoa055643.

18 Jee SH, Sull JW, Park J, et al. Body-mass index and mortality in Korean men and women. N Engl J Med 2006;355:779-87. doi:10.1056/ NEIMoa054017.

19 Freedman DM, Ron E, Ballard-Barbash R, Doody MM, Linet MS. Body mass index and all-cause mortality in a nationwide US cohort. Int J Obes (Lond) 2006;30:822-9. doi:10.1038/sj.ijo.0803193.

20 Pischon T, Boeing H, Hoffmann K, et al. General and abdominal adiposity and risk of death in Europe. N Engl I Med 2008;359:210520. doi:10.1056/NEJMoa0801891.

21 Zhang X, Shu XO, Chow WH, et al. Body mass index at various ages and mortality in Chinese women: impact of potential methodological biases. Int J Obes (Lond) 2008;32:1130-6. doi:10.1038/ijo.2008.63.

22 Boggs DA, Rosenberg L, Cozier YC, et al. General and abdominal obesity and risk of death among black women. N Engl J Med 2011;365:901-8. doi:10.1056/NEJMoa1104119.

23 Masters RK, Powers DA, Link BG. Obesity and US mortality risk over the adult life course. Am J Epidemiol 2013;177:431-42. doi:10.1093/ aje/kws325.

24 Park SY, Wilkens LR, Murphy SP, Monroe KR, Henderson BE, Kolonel $\mathrm{LN}$. Body mass index and mortality in an ethnically diverse population: the Multiethnic Cohort Study. Eur J Epidemiol 2012;27:489-97. doi:10.1007/s10654-012-9695-5.

25 Zheng W, McLerran DF, Rolland B, et al. Association between body-mass index and risk of death in more than 1 million Asians. $N$ Engl J Med 2011;364:719-29.

26 Flegal KM, Kit BK, Orpana H, Graubard BI. Association of all-cause mortality with overweight and obesity using standard body mass index categories: a systematic review and meta-analysis. JAMA 2013;309:71-82. doi:10.1001/jama.2012.113905.

27 Lee IM, Manson JE, Hennekens CH, Paffenbarger RS Jr. Body weight and mortality. A 27-year follow-up of middle-aged men. JAMA 1993;270:2823-8. doi:10.1001/jama.1993.03510230061036.

28 Norrish A, North D, Yee RL, Jackson R. Do cardiovascular disease risk factors predict all-cause mortality?!nt J Epidemiol 1995;24:908-14. doi:10.1093/ije/24.5.908

29 Chyou PH, Burchfiel CM, Yano K, et al. Obesity, alcohol consumption, smoking, and mortality. Ann Epidemiol 1997;7:311-7. doi:10.1016/ S1047-2797(97)00019-7.

30 Lindsted KD, Singh PN. Body mass and 26-year risk of mortality among women who never smoked: findings from the Adventist Mortality Study. Am J Epidemiol 1997;146:1-11. doi:10.1093/ oxfordjournals.aje.a009185.

31 Lindsted KD, Singh PN. Body mass and 26 y risk of mortality among men who never smoked: a re-analysis among men from the Adventist Mortality Study. Int J Obes Relat Metab Disord 1998;22:544-8. doi:10.1038/sj.ijo.0800623.

32 Maskarinec G, Meng L, Kolonel LN. Alcohol intake, body weight, and mortality in a multiethnic prospective cohort. Epidemiology 1998;9:654-61. doi:10.1097/00001648-199811000-00016.

33 Yuan JM, Ross RK, Gao YT, Yu MC. Body weight and mortality: a prospective evaluation in a cohort of middle-aged men in Shanghai, China. Int J Epidemiol 1998;27:824-32. doi:10.1093/ije/27.5.824. 
34 Baik I, Ascherio A, Rimm EB, et al. Adiposity and mortality in men. Am J Epidemiol 2000;152:264-71. doi:10.1093/aje/152.3.264.

35 Folsom AR, Kushi LH, Anderson KE, et al. Associations of general and abdominal obesity with multiple health outcomes in older women: the lowa Women's Health Study. Arch Intern Med 2000;160:2117-28. doi:10.1001/archinte.160.14.2117.

36 Miyazaki M, Babazono A, Ishii T, et al. Effects of low body mass index and smoking on all-cause mortality among middle-aged and elderly lapanese. J Epidemiol 2002;12:40-4. doi:10.2188/jea.12.40.

37 Stevens J, Cai J, Evenson KR, Thomas R. Fitness and fatness as predictors of mortality from all causes and from cardiovascular disease in men and women in the lipid research clinics study. Am J Epidemiol 2002;156:832-41. doi:10.1093/aje/kwf114.

38 Tsugane S, Sasaki S, Tsubono Y. Under- and overweight impact on mortality among middle-aged Japanese men and women: a 10-y follow-up of IPHC study cohort I. Int I Obes Relat Metab Disord 2002;26:529-37. doi:10.1038/sj.ijo.0801961.

39 Thorogood M, Appleby PN, Key TJ, Mann J. Relation between body mass index and mortality in an unusually slim cohort. J Epidemiol Community Health 2003.57:130-3 doi:10.1136/jech.57.2130.

40 Stevens J, Evenson KR, Thomas O, Cai J, Thomas R. Associations of fitness and fatness with mortality in Russian and American men in the lipids research clinics study. Int J Obes Relat Metab Disord 2004:28:1463-70. doi:10.1038/sj.ijo.0802770.

41 Kuriyama S, Ohmori K, Miura C, et al. Body mass index and mortality in Japan: the Miyagi Cohort Study. J Epidemiol 2004;14(Suppl 1):S33-8. doi:10.2188/jea.14.S33.

42 Hayashi R, Iwasaki M, Otani T, et al. Body mass index and mortality in a middle-aged Japanese cohort. J Epidemiol 2005;15:70-7. doi:10.2188/jea.15.70.

43 Jain MG, Miller AB, Rohan TE, et al. Body mass index and mortality in women: follow-up of the Canadian National Breast Screening Study cohort. Int J Obes (Lond) 2005;29:792-7. doi:10.1038/sj.ijo.0802952.

44 Pajak A, Topór-Madry R, Waśkiewicz A, Sygnowska E. Body mass index and risk of death in middle-aged men and women in Poland. Results of POL-MONICA cohort study. Kardiol Pol 2005;62:95-105, discussion 106-7.

45 van Dam RM, Willett WC, Manson JE, Hu FB. The relationship between overweight in adolescence and premature death in women. Ann Intern Med 2006;145:91-7. doi:10.7326/0003-4819-145-2-200607180-00006.

46 Sai XY, He Y, Men K, et al. All-cause mortality and risk factors in a cohort of retired military male veterans, Xi'an, China: an 18-year follow up study. BMC Public Health 2007;7:290. doi:10.1186/1471-2458-7-290.

47 Matsuo T, Sairenchi T, Iso H, et al. Age- and gender-specific BMI in terms of the lowest mortality in Japanese general population. Obesity (Silver Spring) 2008:16:2348-55. doi:10.1038/oby.2008.342.

48 Hozawa A, Okamura T, Oki I, et al. NIPPON DATA80 Study Group. Relationship between BMI and all-cause mortality in Japan: NIPPON DATA80. Obesity (Silver Spring) 2008;16:1714-7. doi:10.1038/ oby.2008.237.

49 Moore SC, Mayne ST, Graubard BI, et al. Past body mass index and risk of mortality among women. Int J Obes (Lond) 2008;32:730-9. doi:10.1038/sj.ijo.0803801.

50 Korkeila M, Rissanen A, Sørensen TI, Kaprio J. BMI, weight stability and mortality among adults without clinical co-morbidities: a 22-year mortality follow-up in the Finnish twin cohort. Obes Facts 2009;2:344-51. doi:10.1159/000261416.

51 Odegaard AO, Pereira MA, Koh WP, et al. BMI, all-cause and cause-specific mortality in Chinese Singaporean men and women: the Singapore Chinese health study. PLoS One 2010;5:e14000. doi:10.1371/journal.pone.0014000.

52 Pierce BL, Kalra T, Argos M, et al. A prospective study of body mass index and mortality in Bangladesh. Int J Epidemiol 2010:39:1037-45. doi:10.1093/ije/dyp364

53 Vessey M, Yeates D, Flynn S. Factors affecting mortality in a large cohort study with special reference to oral contraceptive use. Contraception 2010;82:221-9. doi:10.1016/j. contraception.2010.04.006.

54 Hwang LC, Chen SC, Chen C). Increased risk of mortality from overweight and obesity in middle-aged individuals from six communities in Taiwan. J Formos Med Assoc 2011;110:290-8. doi:10.1016/S0929-6646(11)60044-2

55 Willett WC, Hu FB, Thun M. Overweight, obesity, and all-cause mortality. JAMA 2013;309:1681. doi:10.1001/jama.2013.3075.

56 Kornitzer M, Dramaix M, Beriot I, Lannoy M, Gheyssens H, Kittel F. Twenty-five-year mortality follow-up in the Belgian Bank Study. Cardiology 1993;82:153-71 doi:10.1159/000175865.

57 Barbagallo CM, Cavera G, Sapienza M, et al. Prevalence of overweight and obesity in a rural southern Italy population and relationships with total and cardiovascular mortality: the Ventimiglia di Sicilia project. Int J Obes Relat Metab Disord 2001;25:185-90. doi:10.1038/sj.ijo.0801321.

58 Johansen $\mathrm{H}$, Semenciw R, Morrison H, et al. Important risk factors for death in adults: a 10-year follow-up of the Nutrition Canada survey cohort. CMA/ 1987;136:823-8.
59 Dey DK, Rothenberg E, Sundh V, Bosaeus I, Steen B. Body mass index weight change and mortality in the elderly. A 15 y longitudinal population study of 70 y olds. Eur / Clin Nutr 2001;55:482-92. doi:10.1038/sj.ejcn.1601208

60 Grabowski DC, Ellis JE. High body mass index does not predict mortality in older people: analysis of the Longitudinal Study of Aging. J Am Geriatr Soc 2001;49:968-79. doi:10.1046/j.1532-5415.2001.49189.x

61 Chang-Claude J, Hermann S, Eilber U, Steindorf K. Lifestyle determinants and mortality in German vegetarians and healthconscious persons: results of a 21-year follow-up. Cancer Epidemiol Biomarkers Prev 2005;14:963-8. doi:10.1158/1055-9965. EPI-04-0696.

62 Dolan CM, Kraemer H, Browner W, Ensrud K, Kelsey JL. Associations between body composition, anthropometry, and mortality in women aged 65 years and older. Am J Public Health 2007;97:913-8. doi:10.2105/AIPH.2005.084178.

63 Orsini N, Bellocco R, Bottai M, Pagano M, Michaelsson K, WolkA. Combined effects of obesity and physical activity in predicting mortality among men. J Intern Med 2008;264:442-51. doi:10.1111/j.1365-2796.2008.01985.x

64 Gulsvik AK, Thelle DS, Mowé M, Wyller TB. Increased mortality in the slim elderly: a 42 years follow-up study in a general population. Eur J Epidemiol 2009·24:683-90 doi:10.1007/s10654-009-9390-3.

65 de Hollander EL, Van Zutphen M, Bogers RP, Bemelmans WJ, De Groot LC. The impact of body mass index in old age on cause-specific mortality. J Nutr Health Aging 2012;16:100-6. doi:10.1007/s12603-011-0077-6.

66 Beleigoli AM, Boersma E, Diniz MdeF, Lima-Costa MF, Ribeiro AL. Overweight and class I obesity are associated with lower 10-year risk of mortality in Brazilian older adults: the Bambui Cohort Study of Ageing. PLoS One 2012;7:e52111. doi:10.1371/journal.pone.0052111.

67 Chen Z, Yang G, Offer A, et al. Body mass index and mortality in China: a 15-year prospective study of 220000 men. Int J Epidemio 2012:41:472-81. doi:10.1093/ije/dyr208.

68 Claessen H, Brenner H, Drath C, Arndt V. Repeated measures of body mass index and risk of health related outcomes. EurJ Epidemiol 2012;27:215-24. doi:10.1007/s10654-012-9669-7.

69 Dobson A, McLaughlin D, Almeida O, et al. Impact of behavioural risk factors on death within 10 years for women and men in their 70s: absolute risk charts. BMC Public Health 2012;12:669. doi:10.1186/1471-2458-12-669.

70 Pan WH, Yeh WT, Chen HJ, et al. The U-shaped relationship between $\mathrm{BMI}$ and all-cause mortality contrasts with a progressive increase in medical expenditure: a prospective cohort study. Asia Pac J Clin Nutr 2012;21:577-87.

71 Rhee CW, Kim JY, Park BJ, Li ZM, Ahn YO. Impact of individual and combined health behaviors on all causes of premature mortality among middle aged men in Korea: the Seoul Male Cohort Study. J Prev Med Public Health 2012;45:14-20. doi:10.3961/jpmph.2012.45.1.14.

72 Strand BH, Kuh D, Shah I, Guralnik J, Hardy R. Childhood, adolescent and early adult body mass index in relation to adult mortality: results from the British 1946 birth cohort. J Epidemiol Community Health 2012;66:225-32. doi:10.1136/jech.2010.110155

73 Choi KM, Cho HJ, Choi HY, et al. Higher mortality in metabolically obese normal-weight people than in metabolically healthy obese subjects in elderly Koreans. Clin Endocrinol (Oxf) 2013;79:364-70. doi:10.1111/cen.12154

74 Dahl AK, Fauth EB, Ernsth-Bravell M, Hassing LB, Ram N, Gerstof D. Body mass index, change in body mass index, and survival in old and very old persons. J Am Geriatr Soc 2013;61:512-8. doi:10.1111/jgs.12158.

75 Hinnouho GM, Czernichow S, Dugravot A, Batty GD, Kivimaki M, Singh-Manoux A. Metabolically healthy obesity and risk of mortality: does the definition of metabolic health matter?Diabetes Care 2013;36:2294-300. doi:10.2337/dc12-1654.

76 Hotchkiss JW, Davies CA, Leyland AH. Adiposity has differing associations with incident coronary heart disease and mortality in the Scottish population: cross-sectional surveys with follow-up. Int J Obes (Lond) 2013;37:732-9. doi:10.1038/ijo.2012.102

77 Ma J, Jemal A, Flanders WD, Ward EM. Joint association of adiposity and smoking with mortality among U.S. adults. Prev Med 2013;56:178-84. doi:10.1016/j.ypmed.2012.12.012.

78 Schmidt M, Johannesdottir SA, Lemeshow S, et al. Obesity in young men, and individual and combined risks of type 2 diabetes, cardiovascular morbidity and death before 55 years of age: a Danish 33-year follow-up study. BMJ Open 2013;3:3. doi:10.1136/bmjopen-2013-002698.

79 Stenholm S, Mehta NK, Elo IT, Heliövaara M, Koskinen S, Aromaa A. Obesity and muscle strength as long-term determinants of all-cause mortality--a 33-year follow-up of the Mini-Finland Health Examination Survey. Int I Obes (Lond) 2014;38:1126-32. doi:10.1038/ijo.2013.214.

80 Takata Y, Ansai T, Soh I, et al. Body mass index and disease-specific mortality in an 80-year-old population at the 12-year follow-up. Arch Gerontol Geriatr 2013;57:46-53. doi:10.1016/i.archger.2013.02.006.

81 Yano Y, Kario K, Ishikawa S, et al. JMS Cohort Study Group. Associations between diabetes, leanness, and the risk of death in the lapanese general population: the Jichi Medical School Cohort Study. Diabetes Care 2013:36:1186-92 doi:10.2337/dc12-1736. 
82 Buys DR, Roth DL, Ritchie CS, et al. Nutritional risk and body mass index predict hospitalization, nursing home admissions, and mortality in community-dwelling older adults: results from the UAB Study of Aging with 8.5 years of follow-up. J Gerontol A Biol Sci Med Sci 2014;69:1146-53. doi:10.1093/gerona/glu024.

83 Clark DO, Gao S, Lane KA, et al. Obesity and 10-year mortality in very old African Americans and Yoruba-Nigerians: exploring the obesity paradox. J Gerontol A Biol Sci Med Sci 2014;69:1162-9. doi:10.1093/ gerona/glu035.

84 Ford DW, Hartman TJ, Still C, et al. Body mass index, poor diet quality, and health-related quality of life are associated with mortality in rural older adults. I Nutr Gerontol Geriatr 2014;33:23-34. doi:10.1080/21551197.2014.875819.

85 Gao S, Jin Y, Unverzagt FW, et al. Cognitive function, body mass index and mortality in a rural elderly Chinese cohort. Arch Public Health 2014;72:9. doi:10.1186/2049-3258-72-9.

86 Ghaem Maralani H, Tai BC, Wong TY, et al. The prognostic role of body mass index on mortality amongst the middle-aged and elderly: a competing risk analysis. Diabetes Res Clin Pract 2014;103:42-50. doi:10.1016/i.diabres.2013.11.025.

87 He Y, Lam TH, Jiang B, et al. Changes in BMI before and during economic development and subsequent risk of cardiovascula disease and total mortality: a 35-year follow-up study in China. Diabetes Care 2014:37:2540-7. doi:10.2337/dc14-0243.

88 Hirani V, Naganathan V, Blyth F, et al. Multiple, but not traditional risk factors predict mortality in older people: the Concord Health and Ageing in Men Project. Age (Dordr) 2014;36:9732. doi:10.1007/ s11357-014-9732-2

89 Kokkinos P, Faselis C, Myers J, et al. Cardiorespiratory fitness and the paradoxical BMI-mortality risk association in male veterans. Mayo Clin Proc 2014;89:754-62. doi:10.1016/j.mayocp.2014.01.029.

90 Lee Y, Kim J, Han ES, Ryu M, Cho Y, Chae S. Frailty and body mass index as predictors of 3-year mortality in older adults living in the community. Gerontology 2014:60:475-82. doi:10.1159/000362330.

91 Liu Y, Chi HJ, Cui LF, et al. The ideal cardiovascular health metrics associated inversely with mortality from all causes and from cardiovascular diseases among adults in a Northern Chinese industrial city. PLoS One 2014;9:e89161. doi:10.1371/journal. pone.0089161.

92 McTigue KM, Chang YF, Eaton C, et al. Severe obesity, heart disease, and death among white, African American, and Hispanic postmenopausal women. Obesity (Silver Spring) 2014;22:801-10. doi:10.1002/oby. 20224

93 Mehta NK, Stenholm S, Elo IT, Aromaa A, Heliövaara M, Koskinen S. Weight histories and mortality among finnish adults: the role of duration and peak body mass index. Epidemiology 2014;25:707-10. doi:10.1097/EDE.0000000000000147.

94 Patel AV, Hildebrand JS, Gapstur SM. Body mass index and all-cause mortality in a large prospective cohort of white and black U.S. Adults. PLoS One 2014;9:e109153. doi:10.1371/journal.pone.0109153.

95 Roh L, Braun J, Chiolero A, Bopp M, Rohrmann S, Faeh D. Swis National Cohort Study Group. Mortality risk associated with underweight: a census-linked cohort of 31,578 individuals with up to 32 years of follow-up. BMC Public Health 2014;14:371. doi:10.1186/1471-2458-14-371.

96 Singh PN, Clark RW, Herring P, Sabaté J, Shavlik D, Fraser GE. Obesity and life expectancy among long-lived Black adults. / Gerontol A Biol Sci Med Sci 2014;69:63-72. doi:10.1093/gerona/glt049.

97 Wu CY, Chou YC, Huang N, Chou YJ, Hu HY, Li CP. Association of body mass index with all-cause and cardiovascular disease mortality in the elderly. PLoS One 2014:9:e102589. doi:10.1371/journal.pone.0102589.

98 Xiao Q, Hsing AW, Park Y, et al. Body mass index and mortality among blacks and whites adults in the Prostate, Lung, Colorectal, and Ovarian (PLCO) cancer screening trial. Obesity (Silver Spring) 2014:22:260-8 doi:10.1002/oby.20412.

99 Yiengprugsawan V, Banwell C, Zhao J, Seubsman SA, Sleigh AC. Relationship between body mass index reference and all-cause mortality: evidence from a large cohort of Thai adults. J Obes 2014;2014:708606. doi:10.1155/2014/708606

100 Shil Hong E, Khang AR, Roh E, et al. Counterintuitive relationship between visceral fat and all-cause mortality in an elderly Asian population. Obesity (Silver Spring) 2015;23:220-7. doi:10.1002/ oby. 20914.

101 Long G, Watkinson C, Brage S, et al. Mortality benefits of populationwide adherence to national physical activity guidelines: a prospective cohort study. EurJ Epidemiol 2015;30:71-9. doi:10.1007/ s10654-014-9965-5.

102 Suemoto CK, Lebrao ML, Duarte YA, Danaei G. Effects of body mass index, abdominal obesity, and type 2 diabetes on mortality in community-dwelling elderly in Sao Paulo, Brazil: analysis of prospective data from the SABE study. J Gerontol A Biol Sci Med Sci 2015:70:503-10. doi:10.1093/gerona/glu165.

103 Burman M, Säätelä S, Carlsson M, Olofsson B, Gustafson Y, Hörnsten C. Body mass index, Mini Nutritional Assessment, and their association with five-year mortality in very old people. J Nutr Health Aging 2015;19:461-7. doi:10.1007/s12603-015-0443-x.
104 Chung WS, Ho FM, Cheng NC, Lee MC, Yeh C). BMI and all-cause mortality among middle-aged and older adults in Taiwan: a population-based cohort study. Public Health Nutr 2015;18:1839-46. doi:10.1017/S136898001400281X.

105 Kumar A, Karmarkar AM, Tan A, et al. The effect of obesity on incidence of disability and mortality in Mexicans aged 50 years and older. Salud Publica Mex 2015;57(Suppl 1):S31-8.

106 Qizilbash N, Gregson J, Johnson ME, et al. BMI and risk of dementia in two million people over two decades: a retrospective cohort study. Lancet Diabetes Endocrinol 2015;3:431-6. doi:10.1016 S2213-8587(15)00033-9.

107 Yi SW, Ohrr H, Shin SA, Yi JJ. Sex-age-specific association of body mass index with all-cause mortality among 12.8 million Korean adults: a prospective cohort study. Int J Epidemiol 2015;44:1696-705; [Epub ahead of print]. doi:10.1093/ije/dyv138.

108 Lu JL, Molnar MZ, Naseer A, Mikkelsen MK, Kalantar-Zadeh K, Kovesdy CP. Association of age and BMI with kidney function and mortality: a cohort study. Lancet Diabetes Endocrinol 2015;3:704-14. doi:10.1016/S2213-8587(15)00128-X.

109 Hong S, Yi SW, Sull JW, Hong JS, Jee SH, Ohrr H. Body mass index and mortality among Korean elderly in rural communities: Kangwha Cohort Study. PLoS One 2015;10:e0117731. doi:10.1371/journal.pone.0117731.

110 Ponce-Garcia I, Simarro-Rueda M, Carbayo-Herencia JA, et al. Group of Vascular Diseases from Albacete. Prognostic value of obesity on both overall mortality and cardiovascular disease in the general population. PLOS One 2015;10:e0127369. doi:10.1371/journal.pone.0127369.

111 Nakade M, Takagi D, Suzuki K, et al. Influence of socioeconomic status on the association between body mass index and cause-specific mortality among older Japanese adults: The AGES Cohort Study. Prev Med 2015;77:112-8. doi:10.1016/j.ypmed.2015.05.015.

112 Dankner R, Shanik M, Roth J, Luski A, Lubin F, Chetrit A. Sex and ethnic-origin specific BMI cut points improve prediction of 40-year mortality: the Israel GOH study. Diabetes Metab Res Rev 2015;31:5306. doi:10.1002/dmrr.2642.

113 Ganna A, Ingelsson E. 5 year mortality predictors in 498,103 UK Biobank participants: a prospective population-based study. Lancet 2015;386:533-40. doi:10.1016/S0140-6736(15)60175-1.

114 Graf CE, Karsegard VL, Spoerri A, et al. Body composition and all-cause mortality in subjects older than 65 y. Am J Clin Nutr 2015;101:760-7. doi:10.3945/ajcn.114.102566.

115 Mirbolouk M, Asgari S, Sheikholeslami F, Mirbolouk F, Azizi F, Hadaegh F. Different obesity phenotypes, and incident cardiovascular disease and mortality events in elderly Iranians: Tehran lipid and glucose study. Geriatr Gerontol Int 2015;15:44956. doi:10.1111/ggi.12295.

116 Pirie K, Peto R, Reeves GK, Green J, Beral V. Million Women Study Collaborators. The 21st century hazards of smoking and benefits of stopping: a prospective study of one million women in the UK. Lancet 2013;381:133-41. doi:10.1016/S0140-6736(12)61720-6.

117 Carter BD, Abnet CC, Feskanich D, et al. Smoking and mortality-beyond established causes. N Engl J Med 2015;372:631-40. doi:10.1056/NEJMsa1407211.

118 Winsløw UC, Rode L, Nordestgaard BG. High tobacco consumption lowers body weight: a Mendelian randomization study of the Copenhagen General Population Study. Int J Epidemiol 2015;44:54050. doi:10.1093/ije/dyu276

119 Tan BH, Fearon KC. Cachexia: prevalence and impact in medicine. Curr Opin Clin NutrMetab Care 2008:11:400-7. doi:10.1097/MCO.0b013e328300ecc1.

120 Willett WC, Dietz WH, Colditz GA. Guidelines for healthy weight. N Engl J Med 1999;341:427-34. doi:10.1056/NEJM199908053410607.

121 Stroup DF, Berlin JA, Morton SC, et al. Meta-analysis of observational studies in epidemiology: a proposal for reporting. Meta-analysis Of Observational Studies in Epidemiology (MOOSE) group. JAMA 2000;283:2008-12. doi:10.1001/jama.283.15.2008.

122 Wells G, Shea B, O'Connell D, et al. The Newcastle-Ottawa Scale (NOS) for assessing the quality of nonrandomised studies in meta-analyses. http://www.ohri.ca/programs/clinical_epidemiology/oxford.asp, Accessed 13.08.2014.

123 DerSimonian R, Laird N. Meta-analysis in clinical trials. Control Clin Trials 1986;7:177-88. doi:10.1016/0197-2456(86)90046-2.

124 Greenland S, Longnecker MP. Methods for trend estimation from summarized dose-response data, with applications to meta-analysis. Am J Epidemiol 1992;135:1301-9.

125 Bagnardi V, Zambon A, Quatto P, Corrao G. Flexible meta-regression functions for modeling aggregate dose-response data, with an application to alcohol and mortality. Am J Epidemiol 2004;159:107786. doi:10.1093/aje/kwh142.

126 Hamling J, Lee P, Weitkunat R, Ambühl M. Facilitating meta-analyses by deriving relative effect and precision estimates for alternative comparisons from a set of estimates presented by exposure level or disease category. Stat Med 2008;27:954-70. doi:10.1002/sim.3013.

127 Higgins JP, Thompson SG. Quantifying heterogeneity in a metaanalysis. Stat Med 2002;21:1539-58. doi:10.1002/sim.1186

128 Egger M, Davey Smith G, Schneider M, Minder C. Bias in meta-analysis detected by a simple, graphical test. BMJ 1997;315:629-34. doi:10.1136/ bmj.315.7109.629. 
129 Begg CB, Mazumdar M. Operating characteristics of a rank correlation test for publication bias. Biometrics 1994;50:1088-101. doi:10.2307/2533446.

130 Multiple Risk Factor Intervention Trial Research Group. Relationship between baseline risk factors and coronary heart disease and total mortality in the Multiple Risk Factor Intervention Trial. Prev Med 1986;15:254-73. doi:10.1016/0091-7435(86)90045-9.

131 Rissanen A, Heliövaara M, Knekt P, Aromaa A, Reunanen A, Maatela J. Weight and mortality in Finnish men. J Clin Epidemiol 1989;42:781-9. doi:10.1016/0895-4356(89)90076-0.

132 Rissanen A, Knekt P, Heliövaara M, Aromaa A, Reunanen A, Maatela J. Weight and mortality in Finnish women. / Clin Epidemiol 1991;44:78795. doi:10.1016/0895-4356(91)90131-R.

133 Ho SC. Health and social predictors of mortality in an elderly Chinese cohort. Am J Epidemiol 1991;133:907-21.

134 Sorkin JD, Muller D, Andres R. Body mass index and mortality in Seventh-day Adventist men. A critique and re-analysis. Int J Obes Relat Metab Disord 1994:18:752-4.

135 Hanson RL, McCance DR, Jacobsson LT, et al. The U-shaped association between body mass index and mortality: relationship with weight gain in a Native American population. J Clin Epidemio 1995:48:903-16. doi:10.1016/0895-4356(94)00217-E.

136 Seidell JC, Verschuren WM, van Leer EM, Kromhout D. Overweight, underweight, and mortality. A prospective study of 48,287 men and women. Arch Intern Med 1996;156:958-63. doi:10.1001/ archinte.1996.00440090054006

137 Hodge AM, Dowse GK, Collins VR, Zimmet PZ. Mortality in Micronesian Nauruans and Melanesian and Indian Fijians is not associated with obesity. Am J Epidemiol 1996;143:442-55. doi:10.1093/ oxfordjournals.aje.a008764.

138 Seccareccia F, Lanti M, Menotti A, Scanga M. Role of body mass index in the prediction of all cause mortality in over 62,000 men and women. The Italian RIFLE Pooling Project. Risk Factor and Life Expectancy. J Epidemiol Community Health 1998;52:20-6. doi:10.1136/jech 52.1.20.

139 Rosengren A, Wedel H, Wilhelmsen L. Body weight and weight gain during adult life in men in relation to coronary heart disease and mortality. A prospective population study. Eur Heart J 1999;20:269-77. doi:10.1053/euhi.1998.1235.

140 Allison DB, Fontaine KR, Manson JE, Stevens J, Vanltallie TB. Annual deaths attributable to obesity in the United States. JAMA 1999.282:1530-8 doi:10.1001/jama.282.16.1530.

141 Østbye T, Steenhuis R, Wolfson C, Walton R, Hill G. Predictors of five-year mortality in older Canadians: the Canadian Study of Health and Aging. J Am Geriatr Soc 1999; 47:1249-54. doi:10.1111/j.1532-5415.1999.tb05207.x

142 Andersen LB, Schnohr P, Schroll M, Hein HO. All-cause mortality associated with physical activity during leisure time, work, sports, and cycling to work. Arch Intern Med 2000;160:1621-8. doi:10.1001/ archinte.160.11.1621.

143 Fortes C, Forastiere F, Farchi S, Rapiti E, Pastori G, Perucci CA. Diet and overall survival in a cohort of very elderly people. Epidemiology 2000:11:440-5. doi:10.1097/00001648-200007000-00013.

144 Haapanen-Niemi N, Miilunpalo S, Pasanen M, Vuori I, Oja P, Malmberg J. Body mass index, physical inactivity and low level of physical fitness as determinants of all-cause and cardiovascular disease mortality--16 y follow-up of middle-aged and elderly men and women. Int J Obes Relat Metab Disord 2000;24:1465-74. doi:10.1038/sj.ijo.0801426.

145 Hara M, Mori M, Shono N, Higaki Y, Nishizumi M. Lifestyle-related risk factors for total and cancer mortality in men and women. Environ Health Prev Med 2000;5:90-6. doi:10.1265/ehpm.2000.90.

146 Strawbridge WJ, Wallhagen MI, Shema SI. New NHLBI clinical guidelines for obesity and overweight: will they promote health?Am Public Health 2000;90:340-3. doi:10.2105/AJPH.90.3.340.

147 Katzmarzyk PT, Craig CL, Bouchard C. Original article underweight, overweight and obesity: relationships with mortality in the 13-year follow-up of the Canada Fitness Survey. J Clin Epidemiol 2001;54:91620. doi:10.1016/S0895-4356(01)00356-0.

148 Niverthi M, Ivanovic B. Body mass index and mortality in an insured population. J Insur Med 2001;33:321-8

149 Wannamethee SG, Shaper AG, Walker M. Weight change, body weight and mortality: the impact of smoking and ill health. Int J Epidemio 2001:30:777-86. doi:10.1093/ije/30.4.777.

150 Osler M, Heitmann BL, Gerdes LU, Jørgensen LM, Schroll M. Dietary patterns and mortality in Danish men and women: a prospective observational study. Br J Nutr 2001;85:219-25. doi:10.1079/ BJN2000240.

151 Farrell SW, Braun L, Barlow CE, Cheng YJ, Blair SN. The relation of body mass index, cardiorespiratory fitness, and all-cause mortality in women Obes Res 2002;10:417-23. doi:10.1038/oby.2002.58.

152 Miller MD, Crotty M, Giles LC, et al. Corrected arm muscle area: an independent predictor of long-term mortality in community-dwelling older adults?] Am Geriatr Soc 2002;50:1272-7. doi:10.1046/j.1532-5415.2002.50316.x

153 Wang Z, Hoy WE. Body mass index and mortality in aboriginal Australians in the Northern Territory. Aust N Z J Public Healt 2002;26:305-10. doi:10.1111/j.1467-842X.2002.tb00176.x.
154 Somes GW, Kritchevsky SB, Shorr RI, Pahor M, Applegate WB. Body mass index, weight change, and death in older adults: the systolic hypertension in the elderly program. Am J Epidemiol 2002;156:132-8. doi:10.1093/aje/kwf019.

155 Lubin F, Lusky A, Chetrit A, Dankner R. Lifestyle and ethnicity play a role in all-cause mortality. J Nutr 2003;133:1180-5.

156 Hosegood V, Campbell OM. Body mass index, height, weight, arm circumference, and mortality in rural Bangladeshi women: a 19-y longitudinal study. Am J Clin Nutr 2003;77:341-7.

157 Sundquist K, Qvist J, Sundquist J, Johansson SE. Frequent and occasional physical activity in the elderly: a 12-year follow-up study of mortality. Am J Prev Med 2004;27:22-7. doi:10.1016/j. amepre.2004.03.011.

158 Maru S, van der Schouw YT, Gimbrère CH, Grobbee DE, Peeters PH. Body mass index and short-term weight change in relation to mortality in Dutch women after age 50 y. Am J Clin Nutr 2004:80:231-6.

159 Hu FB, Willett WC, Li T, Stampfer MJ, Colditz GA, Manson JE. Adiposity as compared with physical activity in predicting mortality among women. N Engl I Med 2004:351:2694-703. doi:10.1056/NEJMoa042135.

$160 \mathrm{Hu}$ G, Tuomilehto J, Silventoinen K, Barengo NC, Peltonen M, Jousilahti $P$. The effects of physical activity and body mass index on cardiovascular, cancer and all-cause mortality among 47212 middle-aged Finnish men and women. Int J Obes (Lond) 2005;29:894902. doi:10.1038/sj.ijo.0802870

161 Nyholm M, Merlo J, Råstam L, Lindblad U. Overweight and all-cause mortality in a Swedish rural population: Skaraborg Hypertension and Diabetes Project. Scand J Public Health 2005;33:478-86. doi:10.1080/14034940510006102.

162 Iribarren C, Jacobs DR, Kiefe Cl, et al. Causes and demographic, medical, lifestyle and psychosocial predictors of premature mortality: the CARDIA study. Soc Sci Med 2005;60:471-82. doi:10.1016/j.socscimed.2004.06.007.

163 Hjartåker A, Adami HO, Lund E, Weiderpass E. Body mass index and mortality in a prospectively studied cohort of Scandinavian women: the women's lifestyle and health cohort study. Eur J Epidemiol 2005;20:747-54. doi:10.1007/s10654-005-2145-x.

164 Gu D, He J, Duan X, et al. Body weight and mortality among men and women in China. JAMA 2006;295:776-83. doi:10.1001/ jama.295.7.776.

165 Tsai SP, Donnelly RP, Wendt JK. Obesity and mortality in a prospective study of a middle-aged industrial population. J Occup Environ Med 2006;48:22-7. doi:10.1097/01.jom.0000184866.49000.e5.

166 Lawlor DA, Hart CL, Hole DJ, Davey Smith G. Reverse causality and confounding and the associations of overweight and obesity with mortality. Obesity (Silver Spring) 2006;14:2294-304. doi:10.1038/oby.2006.269.

167 Price GM, Uauy R, Breeze E, Bulpitt CJ, Fletcher AE. Weight, shape, and mortality risk in older persons: elevated waist-hip ratio, not high body mass index, is associated with a greater risk of death. Am J Clin Nutr 2006;84:449-60

168 Schooling CM, Lam TH, LiZB, et al. Obesity, physical activity, and mortality in a prospective chinese elderly cohort. Arch Intern Med 2006;166:1498-504. doi:10.1001/archinte.166.14.1498.

169 Baldinger B, Schwarz C, Jaggy C. Cardiovascular risk factors, BMI and mortality in a cohort of Swiss males (1976-2001) with high-sumassured life insurance cover. J Insur Med 2006;38:44-53.

170 Ray AL, Semba RD, Walston J, et al. Low serum selenium and total carotenoids predict mortality among older women living in the community: the women's health and aging studies. J Nutr 2006;136:172-6

171 Tice JA, Kanaya A, Hue T, et al. Risk factors for mortality in middle-aged women Arch Intern Med 2006:166:2469-77. doi:10.1001/archinte.166.22.2469

172 Corrada MM, Kawas CH, Mozaffar F, Paganini-Hill A. Association of body mass index and weight change with all-cause mortality in the elderly. Am J Epidemiol 2006;163:938-49. doi:10.1093/aje/kwj114.

173 Smith TC, Wingard DL, Smith B, Kritz-Silverstein D, Barrett-Connor E. Walking decreased risk of cardiovascular disease mortality in older adults with diabetes. / Clin Epidemiol 2007;60:309-17. doi:10.1016/i. jclinepi.2006.06.013.

174 Gale CR, Martyn CN, Cooper C, Sayer AA. Grip strength, body composition, and mortality. Int J Epidemiol 2007:36:228-35. doi:10.1093/ije/dyl224

175 Janssen I. Morbidity and mortality risk associated with an overweight BMI in older men and women. Obesity (Silver Spring) 2007;15:182740. doi:10.1038/oby.2007.217.

176 Greenberg JA, Fontaine K, Allison DB. Putative biases in estimating mortality attributable to obesity in the US population. Int J Obes (Lond) 2007:31:1449-55. doi:10.1038/sj.ijo.0803615.

177 Al Snih S, Ottenbacher KJ, Markides KS, Kuo YF, Eschbach K, Goodwin JS. The effect of obesity on disability vs mortality in older Americans. Arch Intern Med 2007:167:774-80. doi:10.1001/archinte.167.8.774.

178 Flegal KM, Graubard BI, Williamson DF, Gail MH. Impact of smoking and preexisting illness on estimates of the fractions of deaths associated with underweight, overweight, and obesity in the US population. Am J Epidemiol 2007:166:975-82. doi:10.1093/aje/kwm152. 
179 Mazza A, Zamboni S, Tikhonoff V, Schiavon L, Pessina AC, Casiglia E. Body mass index and mortality in elderly men and women from general population. The experience of Cardiovascular Study in the Elderly (CASTEL). Gerontology 2007;53:36-45. doi:10.1159/000095783.

180 Simpson JA, MacInnis RJ, Peeters A, Hopper JL, Giles GG, English DR. A comparison of adiposity measures as predictors of all-cause mortality: the Melbourne Collaborative Cohort Study. Obesity (Silver Spring) 2007;15:994-1003. doi:10.1038/oby.2007.622

181 Locher IL, Roth DL, Ritchie CS, et al. Body mass index, weight loss, and mortality in community-dwelling older adults. J Gerontol A Biol Sci Med Sci 2007;62:1389-92. doi:10.1093/gerona/62.12.1389.

182 Fujino Y. Japan Collaborative Cohort Study for Evaluation of Cancer. Anthropometry, development history and mortality in the Japan Collaborative Cohort Study for Evaluation of Cancer (JACC). Asian Pac J Cancer Prev 2007;8(Suppl):105-12

183 Gelber RP, Kurth T, Manson JE, Buring JE, Gaziano JM. Body mass index and mortality in men: evaluating the shape of the association. Int J Obes (Lond) 2007;31:1240-7. doi:10.1038/sj.ijo.0803564

184 Luchsinger JA, Patel B, Tang MX, Schupf N, Mayeux R. Body mass index, dementia, and mortality in the elderly. J Nutr Health Aging 2008;12:127-31. doi:10.1007/BF02982565

185 Kivimäki M, Ferrie JE, Batty GD, et al. Optimal form of operationalizing $\mathrm{BMI}$ in relation to all-cause and cause-specific mortality: the original Whitehall study. Obesity (Silver Spring) 2008;16:1926-32 doi:10.1038/oby.2008.322

186 Pednekar MS, Hakama M, Hebert JR, Gupta PC. Association of body mass index with all-cause and cause-specific mortality: findings from a prospective cohort study in Mumbai (Bombay), India. Int J Epidemiol 2008;37:524-35. doi:10.1093/ije/dyn001.

187 Tsai SP, Wen CP, Chan HT, Chiang PH, Tsai MK, Cheng TY. The effects of pre-disease risk factors within metabolic syndrome on all-cause and cardiovascular disease mortality. Diabetes Res Clin Pract 2008:82:148-56. doi:10.1016/j.diabres.2008.07.016.

188 Sauvaget C, Ramadas K, Thomas G, Vinoda J, Thara S, Sankaranarayanan R. Body mass index, weight change and mortality risk in a prospective study in India. Int J Epidemiol 2008;37:990-1004. doi:10.1093/ije/dyn059.

189 Ringbäck Weitoft G, Eliasson M, Rosén M. Underweight, overweight and obesity as risk factors for mortality and hospitalization. Scand J Public Health 2008;36:169-76. doi:10.1177/1403494807085080.

190 Kulminski AM, Arbeev KG, Kulminskaya IV, et al. Body mass index and nine-year mortality in disabled and nondisabled older U.S. individuals. J Am Geriatr Soc 2008;56:105-10. doi:10.1111/j.1532-5415.2007.01494.x

191 Reuser M, Bonneux LG, Willekens FJ. Smoking kills, obesity disables: a multistate approach of the US Health and Retirement Survey. Obesity (Silver Spring) 2009:17:783-9. doi:10.1038/oby.2008.640.

192 Ferrie JE, Singh-Manoux A, Kivimäki M, et al. Cardiorespiratory risk factors as predictors of 40-year mortality in women and men. Heart 2009:95:1250-7. doi:10.1136/hrt.2008.164251.

193 Guallar-Castillón P, Balboa-Castillo T, López-García E, et al. BMI, waist circumference, and mortality according to health status in the older adult population of Spain. Obesity (Silver Spring) 2009;17:2232-8. doi:10.1038/oby.2009.115

194 Walter S, Kunst A, Mackenbach J, Hofman A, Tiemeier H. Mortality and disability: the effect of overweight and obesity. Int J Obes (Lond) 2009:33:1410-8, doi:10.1038/ijo.2009.176.

195 Klenk J, Nagel G, Ulmer H, et al. VHM\&PP Study Group. Body mass index and mortality: results of a cohort of 184,697 adults in Austria. Eur J Epidemiol 2009;24:83-91. doi:10.1007/s10654-009-9312-4.

196 Wändell PE, Carlsson AC, Theobald H. The association between BMI value and long-term mortality. Int J Obes (Lond) 2009;33:577-82 doi:10.1038/ijo.2009.36

197 Stessman J, Jacobs JM, Ein-Mor E, Bursztyn M. Normal body mass index rather than obesity predicts greater mortality in elderly people: the Jerusalem longitudinal study. J Am Geriatr Soc 2009;57:2232-8. doi:10.1111/j.1532-5415.2009.02567.x

198 Cesari M, Pahor M, Lauretani F, et al. Skeletal muscle and mortality results from the InCHIANTI Study. J Gerontol A Biol Sci Med Sci 2009;64:377-84. doi:10.1093/gerona/gln031.

199 Neovius M, Sundström J, Rasmussen F. Combined effects of overweight and smoking in late adolescence on subsequent mortality: nationwide cohort study. BMJ 2009;338:b496. doi:10.1136/bmj.b496.

200 Iversen L, Hannaford PC, Lee AJ, Elliott AM, Fielding S. Impact of lifestyle in middle-aged women on mortality: evidence from the Royal College of General Practitioners' Oral Contraception Study. Br J Gen Pract 2010;60:563-9. doi:10.3399/bjgp10X515052.

201 Orpana HM, Berthelot JM, Kaplan MS, Feeny DH, McFarland B, Ross NA. BMI and mortality: results from a national longitudinal study of Canadian adults. Obesity (Silver Spring) 2010;18:214-8. doi:10.1038/ oby.2009.191.

202 Arnlöv J, Ingelsson E, Sundström J, Lind L. Impact of body mass index and the metabolic syndrome on the risk of cardiovascular disease and death in middle-aged men. Circulation 2010;121:230-6. doi:10.1161/ CIRCULATIONAHA.109.887521.
203 Vapattanawong P, Aekplakorn W, Rakchanyaban U, Prasartkul P, Porapakkham Y. Obesity and mortality among older Thais: a four year follow up study. BMC Public Health 2010;10:604. doi:10.1186/1471-2458-10-604.

204 Bellocco R, Jia C, Ye W, Lagerros YT. Effects of physical activity, body mass index, waist-to-hip ratio and waist circumference on total mortality risk in the Swedish National March Cohort. Eur J Epidemiol 2010;25:777-88. doi:10.1007/s10654-010-9497-6.

205 Lantz PM, Golberstein E, House JS, Morenoff J. Socioeconomic and behavioral risk factors for mortality in a national 19-year prospective study of U.S. adults. Soc Sci Med 2010;70:1558-66. doi:10.1016/j. socscimed.2010.02.003.

206 Berraho M, Nejiari C, Raherison C, et al. Body mass index, disability, and 13-year mortality in older French adults. J Aging Health 2010;22:68-83. doi:10.1177/0898264309349422.

207 Atlantis E, Browning C, Kendig H. Body mass index and unintentional weight change associated with all-cause mortality in olde Australians: the Melbourne Longitudinal Studies on Healthy Ageing (MELSHA). Age Ageing 2010;39:643-6. doi:10.1093/ageing/afq073.

208 Nagai M, Kuriyama S, Kakizaki M, et al. Effect of age on the association between body mass index and all-cause mortality: the Ohsaki cohort study. J Epidemiol 2010;20:398-407. doi:10.2188/jea.JE20090204.

209 Byun W, Sieverdes JC, Sui X, et al. Effect of positive health factors and all-cause mortality in men. Med Sci Sports Exerc 2010;42:1632-8. doi:10.1249/MSS.0b013e3181d43f29.

210 Carlsson S, Andersson T, de Faire U, Lichtenstein P, Michaëlsson K, Ahlbom A. Body mass index and mortality: is the association explained by genetic factors? Epidemiology 2011;22:98-103. doi:10.1097/EDE.0b013e3181fce2a2.

211 Klijs B, Mackenbach JP, Kunst AE. Obesity, smoking, alcohol consumption and years lived with disability: a Sullivan life table approach. BMC Public Health 2011;11:378. doi:10.1186/1471-2458-11-378.

212 Lin WY, Tsai SL, Albu JB, et al. Body mass index and all-cause mortality in a large Chinese cohort. CMAl 2011;183:E329-36. doi:10.1503/ cmaj.100303.

213 Lisko I, Tiainen K, Stenholm S, Luukkaala T, Hervonen A, Jylhä M. Body mass index, waist circumference, and waist-to-hip ratio as predictors of mortality in nonagenarians: the Vitality $90+$ Study. J Gerontol A Biol Sci Med Sci 2011;66:1244-50. doi:10.1093/gerona/glr147.

214 Wee CC, Huskey KW, Ngo LH, et al. Obesity, race, and risk for death or functional decline among Medicare beneficiaries: a cohort study. Ann Intern Med 2011;154:645-55. doi:10.7326/0003-4819-154-10-201105170-00003.

215 Puddu PE, Menotti A, Tolonen H, Nedeljkovic S, Kafatos AG. Determinants of 40-year all-cause mortality in the European cohorts of the Seven Countries Study. Eur J Epidemiol 2011;26:595-608. doi:10.1007/s10654-011-9600-7.

216 Cohen-Mansfield J, Perach R. Is there a reversal in the effect of obesity on mortality in old age?) Aging Res 2011;2011:765071. doi:10.4061/2011/765071

217 Niedhammer I, Bourgkard E, Chau N. Lorhandicap Study Group. Occupational and behavioural factors in the explanation of socia inequalities in premature and total mortality: a 12.5-year follow-up in the Lorhandicap study. Eur J Epidemiol 2011;26:1-12. doi:10.1007/ s10654-010-9506-9.

218 Mehta NK, Chang VW. Secular declines in the association between obesity and mortality in the United States. Popul Dev Rev 2011:37:435-51. doi:10.1111/j.1728-4457.2011.00429x

219 Heir T, Erikssen J, Sandvik L. Overweight as predictor of long-term mortality among healthy, middle-aged men: a prospective cohort study. Prev Med 2011:52:223-6.

220 Tognon G, Rothenberg E, Eiben G, Sundh V, Winkvist A, Lissner L. Does the Mediterranean diet predict longevity in the elderly? A Swedish perspective. Age (Dordr) 2011;33:439-50. doi:10.1007/ s11357-010-9193-1.

221 Bessonova L, Marshall SF, Ziogas A, et al. The association of body mass index with mortality in the California Teachers Study. Int J Cancer 2011;129:2492-501. doi:10.1002/ijc.25905.

222 Tsai AC, Hsiao ML. The association of body mass index (BMI) with all-cause mortality in older Taiwanese: results of a national cohort study. Arch Gerontol Geriatr 2012;55:217-20. doi:10.1016/j. archger.2011.08.006

223 Zunzunegui MV, Sanchez MT, Garcia A, Casado JM, Otero A. Body mass index and long-term mortality in an elderly Mediterranean population. J Aging Health 2012;24:29-47. doi:10.1177/0898264311408419.

224 Katzmarzyk PT, Reeder BA, Elliott S, et al. Body mass index and risk of cardiovascular disease, cancer and all-cause mortality. Can J Public Health 2012;103:147-51.

225 Fontaine KR, McCubrey R, Mehta T, et al. Body mass index and mortality rate among Hispanic adults: a pooled analysis of multiple epidemiologic data sets. Int J Obes (Lond) 2012;36:1121-6. doi:10.1038/ijo.2011.194

226 Jerant A, Franks P. Body mass index, diabetes, hypertension, and short-term mortality: a population-based observational study, 2000-2006. J Am Board Fam Med 2012;25:422-31. doi:10.3122/ jabfm.2012.04.110289. 
227 Cohen SS, Signorello LB, Cope EL, et al. Obesity and all-cause mortality among black adults and white adults. Am J Epidemiol 2012;176:431-42. doi:10.1093/aje/kws032.

228 Singh PN, Lindsted KD, Fraser GE. Body weight and mortality among adults who never smoked. Am J Epidemiol 1999;150:1152-64. doi:10.1093/oxfordjournals.aje.a009942.

229 Stevens J, Cai J, Juhaeri , Thun MJ, Wood JL. Evaluation of WHO and NHANES II standards for overweight using mortality rates. J Am Diet Assoc 2000;100:825-7. doi:10.1016/S0002-8223(00)00238-8.

230 Visscher TL, Seidell JC, Menotti A, et al. Underweight and overweight in relation to mortality among men aged $40-59$ and $50-69$ years: the Seven Countries Study. Am J Epidemiol 2000;151:660-6. doi:10.1093/ oxfordjournals.aje.a010260.

231 Visscher TL, Seidell JC, Molarius A, van der Kuip D, Hofman A, Witteman JC. A comparison of body mass index, waist-hip ratio and waist circumference as predictors of all-cause mortality among the elderly: the Rotterdam study. Int I Obes Relat Metab Disord 2001;25:1730-5. doi:10.1038/sj.ijo.0801787.

232 Breeze E, Clarke R, Shipley MJ, Marmot MG, Fletcher AE. Causespecific mortality in old age in relation to body mass index in middle age and in old age: follow-up of the Whitehall cohort of male civil servants. Int J Epidemiol 2006;35:169-78. doi:10.1093/ije/dyi212.

233 Freedman DM, Sigurdson AJ, Rajaraman P, Doody MM, Linet MS, Ron E. The mortality risk of smoking and obesity combined. Am J Prev Med 2006;31:355-62. doi:10.1016/j.amepre.2006.07.022

234 Pednekar MS, Gupta PC, Hebert JR, Hakama M. Joint effects of tobacco use and body mass on all-cause mortality in Mumbai, India: results from a population-based cohort study. Am J Epidemiol 2008;167:33040. doi:10.1093/aje/kwm293.

235 Hart CL, Gruer L, Watt GC. Cause specific mortality, social position, and obesity among women who had never smoked: 28 year cohort study. BMJ 2011;342:d3785. doi:10.1136/bmj.d3785.

236 Hotchkiss JW, Leyland AH. The relationship between body size and mortality in the linked Scottish Health Surveys: cross-sectional surveys with follow-up. Int J Obes (Lond) 2011;35:838-51. doi:10.1038/ijo.2010.207.

237 Park Y, Hartge P, Moore SC, Kitahara CM, Hollenbeck AR, Berrington de Gonzalez A. Body mass index and mortality in non-Hispanic black adults in the NIH-AARP Diet and Health Study. PLoS One 2012;7:e50091. doi:10.1371/journal.pone.0050091.

238 Joshy G, Korda RJ, Bauman A, Van Der Ploeg HP, Chey T, Banks E. Investigation of methodological factors potentially underlying the apparently paradoxical findings on body mass index and all-cause mortality. PLoS One 2014:9:e88641. doi:10.1371/journal. pone.0088641.

239 Cao B. Estimating the Effects of Obesity and Weight Change on Mortality Using a Dynamic Causal Model. PLoS One 2015;10:e0129946. doi:10.1371/journal.pone.0129946.

240 Manson JE, Colditz GA, Stampfer MJ, et al. A prospective study of obesity and risk of coronary heart disease in women. N Engl J Med 1990;322:882-9. doi:10.1056/NEJM199003293221303.

241 Bhaskaran K, Douglas I, Forbes H, dos-Santos-Silva I, Leon DA, Smeeth L. Body-mass index and risk of 22 specific cancers: a population-based cohort study of $5 \bullet 24$ million UK adults. Lancet 2014:384:755-65. doi:10.1016/S0140-6736(14)60892-8.

242 Gaudet MM, Kitahara CM, Newton CC, et al. Anthropometry and head and neck cancer:a pooled analysis of cohort data. Int J Epidemio 2015:44:673-81. doi:10.1093/ije/dyv059.

243 Reeves GK, Pirie K, Beral V, Green J, Spencer E, Bull D. Million Women Study Collaboration. Cancer incidence and mortality in relation to body mass index in the Million Women Study: cohort study. BMJ 2007:335:1134. doi:10.1136/bmj.39367.495995.AE

244 Behrens G, Matthews CE, Moore SC, Hollenbeck AR, Leitzmann MF. Body size and physical activity in relation to incidence of chronic obstructive pulmonary disease. CMA/ 2014;186:E457-69. doi:10.1503/cmaj.140025.

245 Sun Q, van Dam RM, Spiegelman D, Heymsfield SB, Willett WC, Hu FB Comparison of dual-energy $\mathrm{x}$-ray absorptiometric and anthropometric measures of adiposity in relation to adiposity-related biologic factors. Am J Epidemiol 2010;172:1442-54. doi:10.1093/aje/kwq306.

246 Willett K, Jiang R, Lenart E, Spiegelman D, Willett W. Comparison of bioelectrical impedance and BMI in predicting obesity-related medical conditions. Obesity (Silver Spring) 2006;14:480-90. doi:10.1038/oby.2006.63.

247 Field AE, Coakley EH, Must A, et al. Impact of overweight on the risk of developing common chronic diseases during a 10-year period. Arch Intern Med 2001;161:1581-6. doi:10.1001/archinte.161.13.1581.
248 Manson JE, Bassuk SS, Hu FB, Stampfer MJ, Colditz GA, Willett WC Estimating the number of deaths due to obesity: can the divergent findings be reconciled?/ Womens Health (Larchmt) 2007;16:168-76. doi:10.1089/jwh.2006.0080.

249 Byers T. Overweight and mortality among baby boomers--now we're getting personal. N Engl J Med 2006;355:758-60. doi:10.1056/ NEJMp068156.

250 Cerhan JR, Moore SC, Jacobs EJ, et al. A pooled analysis of waist circumference and mortality in 650,000 adults. Mayo Clin Proc 2014:89:335-45. doi:10.1016/i.mayocp.2013.11.011.

251 Carmienke S, Freitag MH, Pischon T, et al. General and abdomina obesity parameters and their combination in relation to mortality: a systematic review and meta-regression analysis. Eur J Clin Nutr 2013;67:573-85. doi:10.1038/ejcn.2013.61

252 Chen H, Zhang SM, Hernán MA, Willett WC, Ascherio A. Weight loss in Parkinson's disease. Ann Neurol 2003;53:676-9. doi:10.1002 ana 10577.

253 Barrett-Connor E, Edelstein SL, Corey-Bloom J, Wiederholt WC. Weight loss precedes dementia in community-dwelling older adults. $/ \mathrm{Am}$ Geriatr Soc 1996;44:1147-52. doi:10.1111/j.1532-5415.1996. tb01362.x.

254 Stevens J, Juhaeri, Cai J. Changes in body mass index prior to baseline among participants who are ill or who die during the early years of follow-up. Am I Epidemiol 2001:153:946-53 doi:10.1093/ aje/153.10.946

255 Rumpel C, Harris TB, Madans J. Modification of the relationship between the Quetelet index and mortality by weight-loss history among older women. Ann Epidemiol 1993;3:343-50. doi:10.1016/1047-2797(93)90060-H.

256 Spencer EA, Appleby PN, Davey GK, Key TJ. Validity of self-reported height and weight in 4808 EPIC-Oxford participants. Public Health Nutr 2002;5:561-5. doi:10.1079/PHN2001322

257 Bes-Rastrollo M, Sabaté J, Jaceldo-Siegl K, Fraser GE. Validation of self-reported anthropometrics in the Adventist Health Study 2. BMC Public Health 2011;11:213. doi:10.1186/1471-2458-11-213.

258 Lee DH, Shin A, Kim J, Yoo KY, Sung J. Validity of self-reported height and weight in a Korean population. J Epidemiol 2011;21:30-6. doi:10.2188/jea.JE20100058

259 Campbell PT, Newton CC, Patel AV, Jacobs EJ, Gapstur SM. Diabetes and cause-specific mortality in a prospective cohort of one million U.S adults. Diabetes Care 2012;35:1835-44. doi:10.2337/dc12-0002.

260 Chan DS, Vieira AR, Aune D, et al. Body mass index and survival in women with breast cancer-systematic literature review and meta-analysis of 82 follow-up studies. Ann Oncol 2014;25:1901-14. doi:10.1093/annonc/mdu042.

261 Campbell PT, Newton CC, Dehal AN, Jacobs EJ, Patel AV, Gapstur SM Impact of body mass index on survival after colorectal cancer diagnosis: the Cancer Prevention Study-II Nutrition Cohort. / Clin Oncol 2012;30:42-52. doi:10.1200/JC0.2011.38.0287.

262 Nilsson M, Johnsen R, Ye W, Hveem K, Lagergren J. Obesity and estrogen as risk factors for gastroesophageal reflux symptoms. JAMA 2003;290:66-72. doi:10.1001/jama.290.1.66.

263 Kamat P, Wen S, Morris J, Anandasabapathy S. Exploring the association between elevated body mass index and Barrett's esophagus: a systematic review and meta-analysis. Ann Thorac Surg 2009;87:655-62. doi:10.1016/j.athoracsur.2008.08.003.

264 Okabayashi K, Ashrafian H, Hasegawa H, et al. Body mass index category as a risk factor for colorectal adenomas: a systematic review and meta-analysis. Am J Gastroenterol 2012;107:1175-85, quiz 1186. doi:10.1038/ajg.2012.180.

265 Calle EE. Obesity and cancer. BMJ 2007;335:1107-8. doi:10.1136/ bmj.39384.472072.80.

266 Yang L, Zhou M, Smith M, et al. Body mass index and chronic obstructive pulmonary disease-related mortality: a nationally representative prospective study of 220,000 men in China. Int J Epidemiol 2010;39:1027-36. doi:10.1093/ije/dyq051

267 Davey Smith G, Sterne JA, Fraser A, Tynelius P, Lawlor DA, Rasmussen $\mathrm{F}$. The association between $\mathrm{BMI}$ and mortality using offspring $\mathrm{BMI}$ as an indicator of own BMI: large intergenerational mortality study. BM 2009;339:b5043. doi:10.1136/bmj.b5043.

(c) BMJ Publishing Group Ltd 2016

Appendix 1: Details of searches

Appendix 2: Supplementary tables A-L

Appendix 3: Supplementary figures A-Q 